\title{
¿Satellite Perspectives of Sea Surface Temperature Diurnal Warming on Atmospheric Moistening and Radiative Heating during MJO
}

\author{
Kyle ItTerly, ${ }^{\mathrm{a}}$ PATRICK TAYlor, ${ }^{\mathrm{b}}$ AND J. BREnt Roberts ${ }^{\mathrm{c}}$ \\ a Science Systems and Applications, Inc., Hampton, Virginia \\ ${ }^{\mathrm{b}}$ NASA Langley Research Center, Hampton, Virginia \\ ${ }^{\mathrm{c}}$ Marshall Space Flight Center, Huntsville, Alabama
}

(Manuscript received 13 May 2020, in final form 23 September 2020)

\begin{abstract}
Diurnal air-sea coupling affects climate modes such as the Madden-Julian oscillation (MJO) via the regional moist static energy budget. Prior to MJO initiation, large-scale subsidence increases (decreases) surface shortwave insolation (winds). These act in concert to significantly warm the uppermost layer of the ocean over the course of a single day and the ocean mixed layer over the course of 1-2 weeks. Here, we provide an integrated analysis of multiple surface, top-ofatmosphere, and atmospheric column observations to assess the covariability related to regions of strong diurnal sea surface temperature (dSST) warming over 44 MJO events between 2000 and 2018 to assess their role in MJO initiation. Combining satellite observations of evaporation and precipitation with reanalysis moisture budget terms, we find $30 \%-50 \%$ enhanced moistening over high-dSST regions during late afternoon using either ERA5 or MERRA-2 despite large model biases. Diurnally developing moisture convergence, only modestly weaker evaporation, and diurnal minimum precipitation act to locally enhance moistening over broad regions of enhanced diurnal warming, which rectifies onto the larger scale. Field campaign ship and sounding data corroborate that strong dSST periods are associated with reduced middle-tropospheric humidity and larger diurnal amplitudes of surface warming, evaporation, instability, and column moistening. Further, we find greater daytime increases in low cloud cover and evidence of enhanced radiative destabilization for the top 50th dSST percentile. Together, these results support that dSST warming acts in concert with large-scale dynamics to enhance moist static energy during the suppressed to active phase transition of the MJO.
\end{abstract}

KEYWORDS: Madden-Julian oscillation; Atmosphere-ocean interaction; Moisture/moisture budget; Radiative fluxes; Microwave observations; Satellite observations

\section{Introduction}

Air-sea coupling on diurnal time scales affects climate modes such as the Madden-Julian oscillation (MJO). Air-sea interactions include fluxes of energy (radiation, latent heat, and sensible heat), water mass (precipitation and evaporation), momentum (via wind stress and surface drag), and chemical and biological constituents (DeMott et al. 2015). A fusion of datasets derived from modern satellite instruments enables the long-term study of the diurnal cycle of air-sea interactions over the tropical Indian Ocean prior to MJO onset in order to elucidate its influence on MJO initiation.

Combined with a reduction in upper ocean mixing associated with the quiescent flow, solar radiation can significantly warm the uppermost layer of the ocean over the course of a single day. As a result, diurnal warm layers (DWLs) are commonly imprinted on the sea surface temperature (SST) measurements over the tropical Indian Ocean, especially 12 weeks prior to MJO onset when favorable environmental conditions persist. The ocean surface layer (upper few meters) commonly warms by $1-2 \mathrm{~K}$ (up to $5 \mathrm{~K}$ ) between the morning and early evening depending on wind speed, cloud

¿ Denotes content that is immediately available upon publication as open access.

Corresponding author: Kyle Itterly, kyle.f.itterly@nasa.gov cover, and ocean mixing (Webster et al. 1996; Bellenger et al. 2010; DeMott et al. 2015). We refer to this period of enhanced subsidence prior to the development of widespread precipitating conditions as the suppressed phase throughout this paper; a more rigorous definition based on the MJO index is provided subsequently.

Recent observational studies highlight the importance of DWLs in increasing the regional moist static energy (MSE) during the transition from the MJO suppressed phase to active phase (Ruppert and Johnson 2015; Ruppert 2016). Modeling studies corroborate the importance of including diurnal air-sea coupling showing that MJO forecast skill improves when properly resolving the diurnal cycle of upper-ocean heat transfer (Woolnough et al. 2007; Zhao and Nasuno 2020). Specifically, models better simulate MJO propagation and active phase strength when including this coupling (Klingaman and Woolnough 2014). Bernie et al. (2008) find increased MJO amplitude and better coherence with observations in a coupled general circulation model when properly resolving the diurnal coupling frequency and upper ocean to capture the diurnal warming.

DeMott et al. (2016) use daily mean ERA-Interim boreal winter data between 1986 and 2013 to analyze the role of intraseasonal SST fluctuations on the modulation of the vertically integrated moist static energy (MSE) budget and tendency over the MJO cycle. They estimate the "SST effect" by projecting a daily, smoothed SST time series onto the intraseasonal MSE budget and MSE tendency and analyzing 
their differences. The SST effect accounts for $5 \%-10 \%$ of the intraseasonal MSE tendency, thus revealing a nonnegligible impact of ocean feedbacks on the MJO evolution (DeMott et al. 2016).

The approach above may underestimate the impact of ocean feedbacks on the MJO because it is unable to resolve boundary layer convergence driven by SST gradients. Alternatively, de Szoeke and Maloney (2020) use a model of mixed layer winds to estimate column-integrated MSE convergence over the MJO cycle due to SST gradients. The small $(0.3 \mathrm{~K}) \mathrm{SST}$ anomalies during the suppressed $\mathrm{MJO}$ are shown to drive $\sim 0.25 \mathrm{~mm}_{\text {day }}{ }^{-1} \mathrm{MSE}$ convergence, which is in the right phase to contribute to MJO generation and propagation (de Szoeke and Maloney 2020).

Recent studies utilize limited regional data collected from ships and rawinsonde arrays of the Dynamics of the MJO (DYNAMO) field campaign to hypothesize several pathways through which diabatic processes operating on short time scales influence the MJO (Chen et al. 2015; Ruppert and Johnson 2015; Ruppert 2016). DWLs act to moisten the atmospheric column and prime the lower atmosphere for MJO initiation by limiting the effects of entrainment on parcel buoyancy (Ruppert and Johnson 2015). This is consistent with Waite and Khouider (2010), who show that detraining cumulus congestus moisten the lower troposphere. Similar to a heated land surface, DWLs modulate the probability of low-level cloud development and instability by increasing air-sea fluxes of heat and moisture and reducing convective inhibition during the pre-onset MJO (Bellenger et al. 2010; Zhao et al. 2013; Ruppert 2016). Ciesielski et al. (2017) find tilted structures in the time-height plots of longwave and shortwave radiation anomalies when composited \pm 15 days around the DYNAMO MJO due to the prevalence of shallow cumulus during the suppressed phase. They hypothesize that these radiative structures are related to water vapor effects, which they note could be linked to detrainment from the cumuliform clouds. Based on these results, we hypothesize that the MSE convergence associated with low-level cloud development over DWLs is an important source of moisture to the lower free troposphere and further influences MJO initiation through feedbacks on radiative heating.

Although significant progress has been made toward understanding the relationships between diurnal processes and the $\mathrm{MJO}$ in recent years, many questions remain. There exists a lack of observational evidence linking DWLs and the low cloud diurnal cycle to the suppressed phase atmospheric energetics and MJO initiation outside of DYNAMO largely due to sparse in situ measurements over the tropical Indian Ocean.

Herein, we exploit state-of-the-art satellite products to gain process-level understanding in order to evaluate hypotheses suggested by field campaign data and modeling studies. The use of satellite-derived products in the present study enables us to composite the diurnal cycle of cloud properties, moisture budget terms, fluxes, and radiative heating profiles over a much larger area than previous field campaigns. Compositing over many MJO events enables the study of air-sea coupling while reducing noise related to differences in the initial state of the large-scale circulation (Ruppert and Klocke 2019) and ocean (de Szoeke et al. 2015). Thus, we aim to provide more spatially extensive observational analyses of these processes in relation to the development of DWLs to characterize their importance to MJO development.

\section{Data}

\section{a. Observations}

\section{1) CERES}

The Clouds and the Earth's Radiant Energy System (CERES; Wielicki et al. 1996) synoptic edition 4A product (Young et al. 1998; Doelling et al. 2013, 2016) provides 1hourly radiative fluxes at the surface, four atmospheric levels $(850,500,200$, and $70 \mathrm{hPa})$, and the top of the atmosphere (TOA). Cloud properties are retrieved at four layers: low (surface to $700 \mathrm{hPa}$ ), middle $(700-500 \mathrm{hPa})$, middle-high (500-300 hPa), and high (300-50 hPa). Geostationary (GEO) satellite retrievals are normalized by and combined with fluxes retrieved by the CERES instrument on Terra and Aqua MODIS to obtain a diurnally complete record (Doelling et al. 2013, 2015, 2016). Due to the calibration and interpolation process, GEO artifacts are sometimes present in the diurnal cycle (Doelling et al. 2016).

In-atmosphere fluxes use satellite-derived cloud and aerosol properties together with the Langley $\mathrm{Fu}-\mathrm{Liou}$ radiative transfer model (RTM; Fu and Liou 1993; Fu et al. 1997; Kratz and Rose 1999; Kato et al. 1999, 2005; Rose et al. 2005). The Surface and Atmospheric Radiation Budget (SARB) products use TOA flux observations from CERES and retrieved cloud properties (Minnis et al. 2011) as constraints to the RTM to iteratively balance the energy budget using cloud overlap assumptions along with atmospheric model data (Kato et al. 2019).

Temperature and humidity profiles used in the RTM are from the Goddard Earth Observing System (GEOS-5.4.1) at 3hourly temporal resolution (CERES Science Team 2015). Skin temperatures are assimilated at 3-hourly resolution. Over ocean, the National Centers for Environmental Prediction (NCEP) Global Data Assimilation System (GDAS) provides SSTs. The NCEP GDAS SST is derived from the Reynolds et al. (2002) optimum interpolation daily SST analysis, using both in situ and satellite data. When collocated and compared to buoy observations, the diurnal cycle of SST used in CERES SYN1deg Ed4A is too weak over the tropical Indian Ocean (D. Rutan 2019, personal communication). The lack of diurnal variability in skin temperature will lead to diurnal cycle errors in the upwelling longwave surface flux response to diurnal SST changes. Despite this limitation, we expect a warming signal to show up in the daily average. Additionally, the atmospheric response to DWLs should be extractable in the observed clear-sky TOA fluxes and cloud properties that impact the radiative fluxes.

\section{2) IMERG}

The recently released Integrated Multi-satellite Retrievals for Global Precipitation Measurement (IMERG) version 06 product provides half-hourly $0.1^{\circ} \times 0.1^{\circ}$ estimates of random 
error, a quality flag, and a gauge-corrected global "best guess" precipitation rate $(P)$ (Huffman et al. 2019a). Retrievals of $P$ are derived from sun-synchronous low Earth orbiting microwave (MW) radiometers when available and microwave-calibrated IR estimates are used to fill in gaps. The intercalibrated MW $P$ retrievals from the GPM and TRMM MW imagers (GMI and TMI, respectively) and other sensors are merged to create half-hourly retrievals and gridded to the IMERG Level $30.1^{\circ} \times 0.1^{\circ}$ grid. Conical-scan radiometers are given priority over cross-track scanners, which perform better over ocean than land (Huffman et al. 2019b). An atmospheric motion morphing technique is used to temporally interpolate the microwave data to the IMERG analysis time (Joyce and Xie 2011). Finally, monthly rain gauge information is infused into the multisatellite-only field to create the completed half-hourly calibrated IMERG $P$ (Huffman et al. 2007, 2019b).

Sampling biases arise due to diurnal variations in the availability of microwave retrievals. The lack of a secondary late afternoon $P$ maximum in TRMM 3B42 during the suppressed MJO over the tropical Indian Ocean could be biased by the lack of late afternoon microwave retrievals prior to 2005 (Sakaeda et al. 2017, 2018). Similar sampling limitations apply to IMERG. During the DYNAMO field campaign in late 2011, MW retrievals are most frequently available at 0200-0800 and 1400-2000 LST, which better captures both diurnal $P$ modes compared to the S-Polka radar on Addu Atoll in the Maldives (Sakaeda et al. 2018).

\section{3) SEAFlux}

SeaFlux version 3 (Roberts et al. 2020) provides satellitederived estimates of 1-hourly SST, near-surface meteorology: temperature $(T)$, wind speed $(V)$, specific humidity $(q)$, sensible heat flux (SHF), and latent heat flux (LHF) at $25 \mathrm{~km}^{2}$ resolution. The diurnally varying SST uses the Reynolds Optimally Interpolated version 2.0 AVHRR-only SST (Reynolds et al. 2007) as the base temperature at which there is no diurnal variability. The diurnal warming curve is determined using the estimated daytime warming of Clayson and Bogdanoff (2013) that relies on satellite-observed shortwave radiation and winds; this curve is added to the base temperature. The near-surface meteorology is estimated from the constellation of passive microwave imagers that were also used in the development of the IMERG products. Retrievals of $V, q$, and $T$ use a neural network trained for each sensor against a large observational database and include additional inputs from MERRA-2 to account for water vapor stratification and boundary layer stability (Roberts et al. 2010, 2019). Further, estimates have been intercalibrated using the GPM GMI sensor as a reference standard. Surface turbulent fluxes are computed using the COARE 3.5 algorithm (Edson et al. 2013). The native resolution SeaFlux data are remapped to the $1^{\circ} \times 1^{\circ}$ grid only when matching CERES SYN1deg Ed4A products. When matching SeaFlux with reanalysis output, we select the closest SeaFlux grid box center.

\section{4) Research Vessel Roger REVELLE}

During DYNAMO, which captured two complete MJO cycles in late 2011, Research Vessel (R/V) Revelle served as the northeastern sounding station $\left(0^{\circ}, 80.5^{\circ} \mathrm{E}\right)$ in the southern array of four stations along with R/V Mirai and the islands of Diego Garcia and Gan. A two-channel microwave radiometer (23 and $31 \mathrm{GHz}$ ) obtained independent measurements of precipitable water (PW), which show good agreement with the humiditycorrected Vaisala RS92-SGP sounding measurements (Ciesielski et al. 2014). We use the level 4 sounding dataset interpolated to 5$\mathrm{hPa}$ bins and only accept the highest-quality data.

Additionally, R/V Revelle operated as the principal observational base for investigating air-sea interactions associated with the initiation and propagation of the MJO. A sea snake floating thermistor (0.05-m depth) measured SST. SST measurements from IR radiometers and a separate thermistor agree within $\pm 0.1 \mathrm{~K}$. High-frequency near-surface meteorology $(T, q$, and $V)$ is used to estimate bulk fluxes using the COARE 3.0 algorithm. Surface longwave (LW) flux components (LW UP and LW NET) were measured by IR radiometers. To determine the best estimate of $P$, seven rain gauges were used.

\section{b. Reanalysis}

\section{1) ERA5}

ERA5 is the latest reanalysis produced by the European Centre for Medium-Range Weather Forecasts (ECMWF). The data assimilation system uses a four-dimensional variational scheme to produce hourly forecasts from each 12-hourly analysis cycle using spectral coefficients with a triangular truncation of T639 (approximately $0.25^{\circ}$ ) resolution. Here, we use the Copernicus Climate Change Service (C3S) Climate Data Store to convert ERA5 to NetCDF format, which uses bilinear interpolation to produce a $0.25^{\circ} \times 0.25^{\circ}$ regular grid (C3S 2017). ERA5 assimilates a bulk SST that is a blend of satellite retrievals and in situ observations from ships (ECMWF 2015) calibrated to a depth of a few meters to match ship subsurface observations. ERA5 uses version CY41R2 of the Integrated Forecast System (IFS).

The forecast model includes three different parameterizations of near-surface ocean effects: a cool skin, a warm layer, and salinity effects on the saturation specific humidity at the surface (ECMWF 2015). These parameterizations drive the ocean skin temperature in the model, which is not always the same as the bulk SST. The warm layer parameterization in the IFS uses a simple bulk formulation based on similarity temperature profiles (ECMWF 2015). The diurnal cycle of skin temperature is determined by integrating a differential equation between the cool skin and the ocean bulk temperature a few meters deep at each time step. The DWL parameterization scheme in the IFS provides the a priori expectation that ERA5 is better able to simulate diurnal air-sea coupling than other reanalyses. We combine and compare ERA5 total column moisture flux divergence (MFD), $P$, evaporation $(E)$, and PW (C3S 2017) against satellite retrievals of $P$ and $E$ to evaluate the moisture budget sensitivity to dSST strength.

\section{2) MERRA-2}

The Modern-Era Retrospective Analysis for Research and Applications-2 (MERRA-2; Gelaro et al. 2017) is the latest reanalysis produced by the Goddard Modeling and Assimilation 

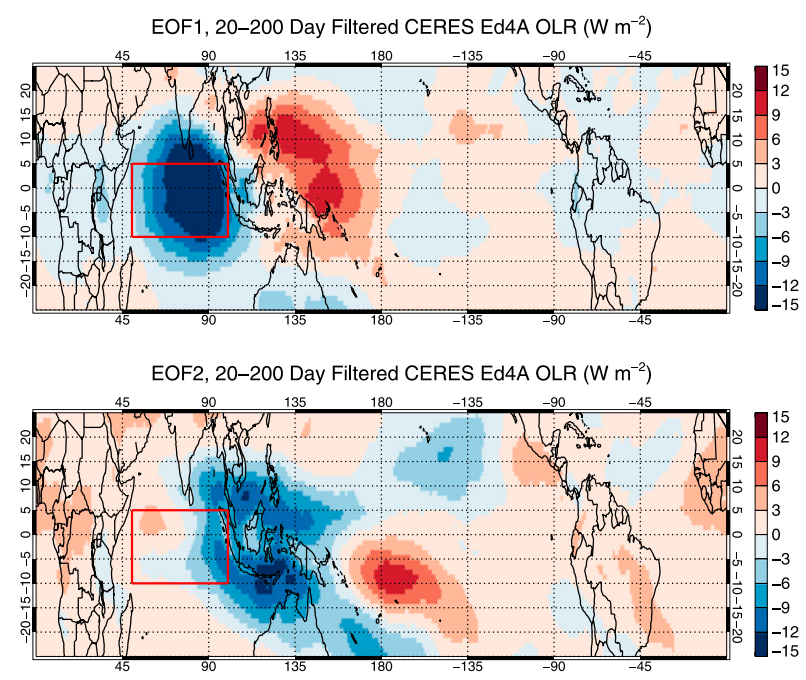

FIG. 1. The near-quadrature pair of empirical orthogonal functions (a) mode 1 and (b) mode 2 used to describe MJO events from empirical orthogonal decomposition of 20-200-day Lanczosfiltered CERES OLR anomalies (anomalies with respect to a \pm 15 -day running window). The study domain $\left(10^{\circ} \mathrm{S}-5^{\circ} \mathrm{N}, 50^{\circ}-\right.$ $100^{\circ} \mathrm{E}$ ) is outlined in red.

Office (GMAO). MERRA-2 uses version 5.12.4 of the GEOS atmospheric model and data assimilation system with horizontal resolution of $0.5^{\circ}$ latitude $\times 0.625^{\circ}$ longitude and vertical resolution of 72 hybrid-eta levels at 1-hourly temporal resolution for $P, E$, MFD, and PW (Molod et al. 2015; GMAO 2015a,b,c). (Table 2 provides a summary of data and model products.)

\section{Methodology}

\section{a. MJO identification}

A primary feature of the MJO is large-scale convection (Madden and Julian 1971); thus, outgoing longwave radiation (OLR) is often used as a key signature to identify MJO events. Matthews (2008) developed and applied an MJO identification technique that relies on the OLR signal together with phase information to identify different variants of the MJO: primary (i.e., no preceding MJO signature) and successive MJO events. Here, we adapt the Matthews (2008) approach to focus more specifically on the transition from the suppressed to active phase. While multivariate methods such as Wheeler and Hendon (2004) highlight both the coupled dynamic and thermodynamic features of the MJO, it is not clear that they are optimal for capturing the initiation of the convective signal (Straub 2013; Kiladis et al. 2014).

We compute tropical $\left(25^{\circ} \mathrm{N} / \mathrm{S}\right)$ OLR anomalies from NASA CERES SYN1deg Ed4A (CERES Science Team 2015) with respect to the annual cycle for the period March 2000 through March 2018. We estimate a daily resolved annual cycle using a 31-day running average. OLR anomalies are bandpassed to retain the 20-200-day period using a Lanczos filter. An empirical orthogonal function (EOF) decomposition of the filtered anomalies results in a near-quadrature pair of EOFs accounting for the first two modes. Modes 1 (Fig. 1a) and 2 (Fig. 1b) explained $7.1 \%$ and $5.0 \%$ of the total variance, respectively.

As in Matthews (2008), we define an MJO index amplitude, Amp [Eq. (1)], and phase angle $\Phi$ [Eq. (2)] using the quadrature pair of PCs $1\left(x_{\mathrm{pc}}\right)$ and $2\left(y_{\mathrm{pc}}\right)$ :

$$
\begin{aligned}
\operatorname{Amp} & =\operatorname{sqrt}\left(x_{\mathrm{pc}}^{2}+y_{\mathrm{pc}}^{2}\right), \\
\Phi & =\tan ^{-1}\left(y_{\mathrm{pc}} / x_{\mathrm{pc}}\right) .
\end{aligned}
$$

With this index, we classify all time periods based on the strength of the MJO amplitude and phase angle. Parsing the phase angle into quadrants distinguishes four broad phases of the MJO: phases A $(315-45), \mathrm{B}(45,135], \mathrm{C}(135,225]$, and D $(225,315]$. Phase $\mathrm{A}$ is associated with a large convective anomaly (negative OLR) centered over the central Indian Ocean with suppressed conditions transitioned to the Pacific warm pool. Phase A is typically followed by phase B, which is indicative of the propagation of large-scale deep convection to the Maritime Continent. Phase $\mathrm{C}$ indicates positive OLR anomalies centered over the central Indian Ocean, with negative OLR anomalies centered over the warm pool to the east of the Maritime Continent. Phase D is associated with an eastward shift of the suppressed conditions (positive OLR) to be centered over the Maritime Continent while the suppressed conditions over the Indian Ocean are eroded and OLR anomalies return to neutral or slightly negative. A sequence of $\mathrm{C}, \mathrm{D}, \mathrm{A}, \mathrm{B}$ thus indicates a MJO progression through suppressed, transition, active, and decay phases, respectively, over the central Indian Ocean.

Further, the MJO index must exceed critical amplitude, $\mathrm{Amp}_{\text {crit }}$ - set to 0.4 in this study - in order to be classified in one of the above four phases. Larger amplitudes indicate that the OLR anomaly field projects strongly onto the leading EOF structures. Days with amplitude below the critical threshold are assigned into a non-MJO (N) category. Classifying all days following these rules results in a daily character sequence used to identify MJO cycles. Further, the sequence is then analyzed to adjust the phases for sensitivity to the critical threshold. Given weather (and observational) noise, it is possible for an event amplitude to slightly graze the critical value only to reemerge the following day. Thus, we follow Matthews (2008) and require transitions to category $\mathrm{N}$ to fall below a lower threshold, $\mathrm{Amp}_{\text {low }}=0.3$, and transitions from $\mathrm{N}$ require crossing $A m p_{h i}=0.5$. Following Matthews (2008), we reduce the full character sequence by eliminating consecutive days in the same phase (e.g., a sequence of NAAABBCDD becomes NABCD). We further restrict our analysis to cycles during the extended boreal winter (October-March).

We focus on the cycle CDA to investigate the transition from suppressed to active conditions over the Indian Ocean. While we do not explicitly require these cycles to be followed by a B phase, approximately $85 \%$ of the MJO events transition to B. Not all MJO events fully propagate eastward despite undergoing a suppressed-to-active phase transition (Kim et al. 2014). Using this approach, we identify 44 CDA boreal winter MJO events between 2000 and 2018 (Fig. 2). To composite the 


\section{START DATE}

$01-17-2018$
$11-28-2017$
$10-09-2017$
$01-24-2017$
$12-26-2016$
$10-19-2016$
$01-31-2016$
$12-10-2015$
$09-21-2015$
$02-23-2015$
$11-21-2014$
$10-21-2014$
$02-06-2014$
$01-11-2014$
$02-18-2013$
$12-27-2012$
$09-19-2012$
$01-21-2012$
$12-17-2011$
$10-28-2011$
$09-21-2011$
$01-02-2011$
$10-22-2010$
$01-06-2010$
$10-02-2009$
$03-05-2009$
$12-27-2008$
$12-27-2007$
$11-07-2007$
$01-21-2007$
$10-19-2006$
$01-13-2006$
$12-11-2005$
$11-20-2004$
$09-27-2004$
$03-05-2004$
$12-09-2003$
$10-05-2003$
$11-13-2002$
$09-27-2002$
$02-23-2002$
$12-15-2001$
$11-21-2000$
$10-16-2000$

Tropical Indian Ocean C>D>A MJO Event Evolution

$$
\begin{array}{l|l|l}
44 & \mathrm{BB} \\
43 & \mathrm{~B} B \\
42 & \mathrm{~A} A \\
41 & \mathrm{~A} A \\
40 & \mathrm{~B} \\
39 & \mathrm{NN} \\
39 & \mathrm{~B} \\
\hline
\end{array}
$$
BBBBBBBBBBBCCCCCCCCPDDDDDDDDDDDDDDDDDDA A ABBBBBBBBBCCCCCCCCDDDDDDDDDAAAAAAAAABBB B B B B B BBBBBBBBCCCCC DDDDDAAAAAAABBBBBBBBB NNNBBBBBBBBBBBBCCCCCDDDDDDDDDDDDAAAAABBBB B B B B B B B B B B B B C C C C DDDDDDDDDDDDDDDDAAAAA B B B B B B B B B B B C C C C C CDDDDDDDDDDDDAAAAAAAAA $01-19-2016$ BBBBBAABBNNNNCCCCCCC DDDDDDDDDDDDDDDDDDDDD

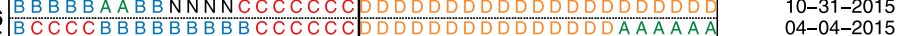
BCCCCBBBBBBBBBCCCCCC DDDDDDDDDDDDDDDAAAAAA A A A A A A B BBBBBBBBCCCC DDDAAAAAAAAAAAABBBBB AAADDDCCCCCCCCCCCCCCPDDDDDDDDDDAAAAAAABBB $11-30-2014$

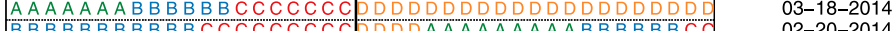
BBBBBBBBBBBCCCCCCCCC PDDDAAAAAAAAABBBBBBCC 02-20-2014 $B$ B B B B B B B B B B B B B CCC CCC DDDD D DDDDDDDDDDDDAAAA $03-30-2013$ AAABBBBBBBBBBBCCCCCCPDDDDDDDDDDDDDDDDDDDQ 02-05-2013 NNNNNNCCCCCCCCCCCCCC DDDDDDDAAAAAAAAAAAAAA 10-29-2012 ABBBBBBBBBBCCCCCCCCC DDDDDDDAAAAAAAAAAAAAA 03-01-2012 B BBBBBBBBBBBCCCCCCCC DDDDDDDDDDAAAAAABBBBB 01-26-2012 AAAAAABBCCCCCCCCCCCCPDDDAAAAAAAAAAABBBBCC 12-07-2011 CCCCCCBBBBBBCCCCCCCC DDDDDDDDDDAAAAAAAAAAA 10-31-2011 A AAAAAABBBBBBCCCCCCC DDDDDDDDDAAAAAAAAAAAA 02-11-2011 CC CBBBBBBBBBBBBCCCCCDDDDDDDDDDDAAAAAAAAAA 12-01-2010 B B B B B BCCCCCCCCCCCCCC DDDDDDDDDDDDDDDDDDDDD 02-15-2010 B B B B B B B B BCCCCCCCC DDDDDDDDDDAAAAAAAAAA 1 $11-11-2009$ B B B BNNNNNCCCCCCCCCCC DDDDDDDDDDAAAAAAAAAAB 04-14-2009 B B B B BBBCCCCCCCCCCCDDDDDDDAAAAAAAABBBBBB 02-05-2009 17 BBBBBBBCCCCCCCCCCCCCDDDDDDDDDDDDAAAAAAAAB

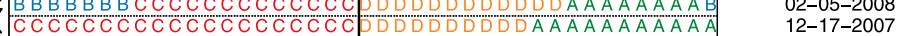

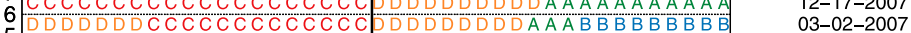

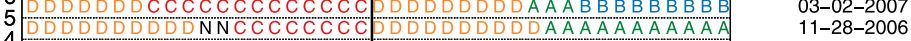

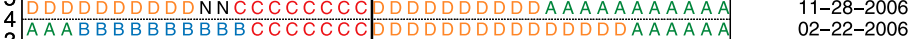
AAABBBBBBBBBBCCCCCCCPDDDDDDDDDDDDDDAAAAAA 02-22-2006 12 B B B B B B BCCCCCCCCCC DDDDDAAAAAAAAAABBBBB $01-20-2006$ 11 NNNNNCCCCCCCCCCCCCCCPDDDDDDDDDAAAAAAAAAAB 12-30-2004 AAABBBCCCCCCCCCCCCCCPDDDDDAAAAAAAAAAAAAAA 11-06-2004 BBBBBBBBBBBBBBBBCCCC DDDDDDDDDDDDDDDDDDDDQ $B B B B B B B B B B B B C C C C C C C C D D D D D D D D D D D D D D D D D D D D D$ $A A A A B B B B C C C C C C C C C C C C$ DDDDDDDDDDAAAAAAAAAA A A B B B B B B B B C C C C C C C C D DDDDDDDDDDDDAAAAAAAA 12-23-2002 A A A A A A A A A A B B B BCCCCCCPDDDDDDDDDDDDDDDDAAAA 11-06-2002

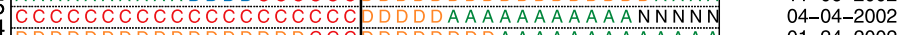
4 (DDDDDDDDDDDDDDDDCCCDDDDDDDDAAAAAAAAAAAAA $01-24-2002$ B B B B B B B B B C C C C C C CCC PDDDDDDDDDDDDDDDDDDDD

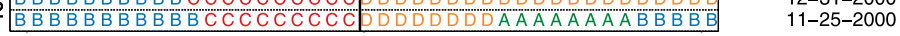

Lag Day

20

$-25-2000$

FIG. 2. The start date, end date, and evolution of MJO phases over 44 boreal winter suppressed $\rightarrow$ transition $\rightarrow$ active $(\mathrm{C} \rightarrow \mathrm{D} \rightarrow \mathrm{A})$ tropical Indian Ocean MJO events between 2000 and 2018 aligned such that the end of the suppressed phase occurs at the midpoint (vertical black line) of the 41-day record length. Non-MJO days are marked as "N" (black); active MJO events outside of the Indian Ocean quadrant are marked as "B" (blue).

evolution of MJO events with distinct propagation characteristics, we align each MJO event relative to "day 0" defined as the start of the transition phase (Fig. 2). The length of each phase varies significantly, ranging between 4 and 21 days (Fig. 2). The yearly frequency of boreal winter CDA MJO events varies between 1 and $4 \mathrm{yr}^{-1} ; 2011$ and 2014 are the most active years (Fig. 2).

\section{b. Compositing of diurnal variables}

Computing daily diurnal sea surface temperature (dSST) warming from the 1-hourly SeaFlux SST requires several steps. First, we convert the 1-hourly SST from UTC to local solar time (LST). Then, we compute dSST as the maximum daytime value (the period between 0500 and 1700 LST) minus a "predawn/nighttime" temperature (the period between 0300 and 0500 LST).

Across all days in Fig. 2, the average dSST exceeds $0.3 \mathrm{~K}$ for portions of the equatorial Indian Ocean (Fig. 3d) and spatial patterns strongly vary by MJO phase. The lowest (highest) OLR values occur in the eastern (western) Indian Ocean off the coast of Sumatra (Figs. 3a-d). Probability density functions of dSST (OLR) are right-skewed (left-skewed) during the suppressed and transition phase (Fig. 3e).
Considering all MJO phases, the most frequent dSST for the tropical Indian Ocean is near $0.2 \mathrm{~K}$ (black line, Fig. 3e). Throughout the paper, we interchangeably refer to dSST exceeding the 50th percentile as DWLs or high-dSST bins. Every MJO event is associated with a distinct background dSST pattern; therefore, using fixed bins across all events and latitudes results in unequal weighting of certain events and areas of ocean. Therefore, we apply two percentile-based methods [see sections $3 b(1)$ and $3 b(2)$ ] to bin and composite distinct MJO events by their relative suppressed phase DWL strength.

\section{1) LAG-EVOLUTION COMPOSITES}

The first compositing method sorts each grid box within the domain into 1 of 4 percentile bins based on its suppressed phase average dSST; the percentiles are computed separately for each MJO event. For lag composites, we remove the boreal winter climatology (Fig. 3d) from each grid box to infer the impact of persistent suppressed phase DWLs on climatological anomalies \pm 14 days from the start of the transition phase. We apply this method to plot the evolution of anomalous nearsurface meteorology and moisture budget terms over a typical MJO C $\rightarrow$ D $\rightarrow$ A cycle for each of the four dSST percentile bins to analyze the influence of DWLs. Additionally, we use 
(a) Phase C

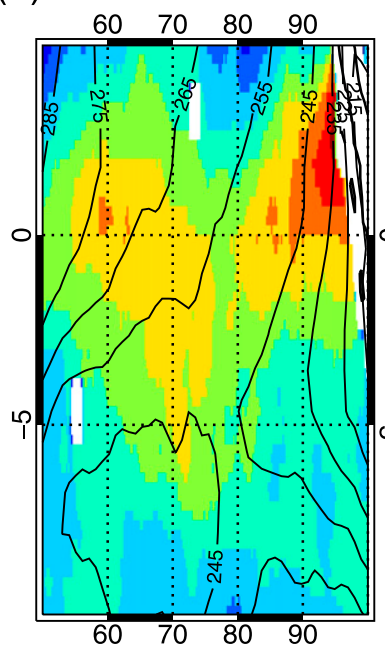

(b) Phase D

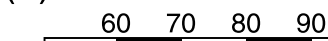

(c) Phase A

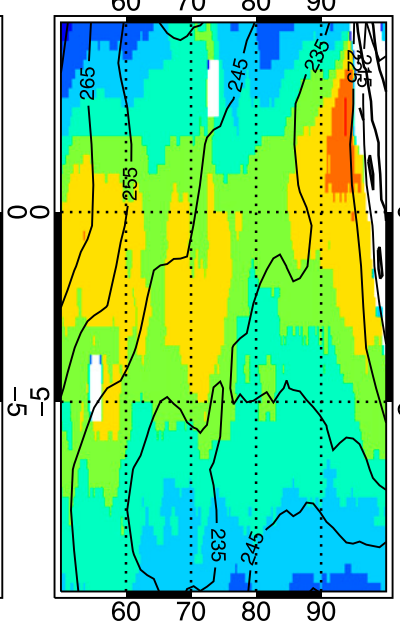

$\begin{array}{llll}60 & 70 & 80 & 90\end{array}$

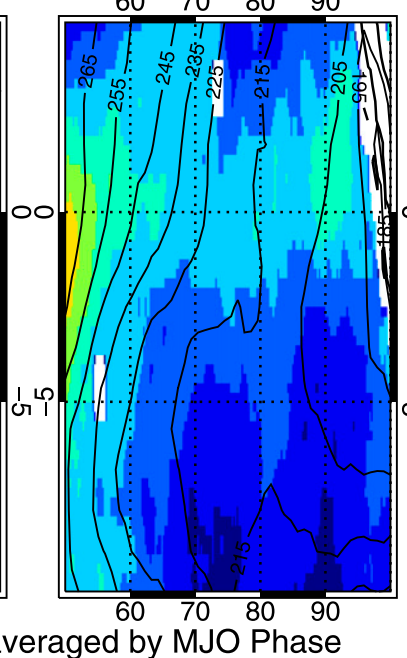

(d) All $(\mathrm{C} / \mathrm{D} / \mathrm{A} / \mathrm{B} / \mathrm{N})$

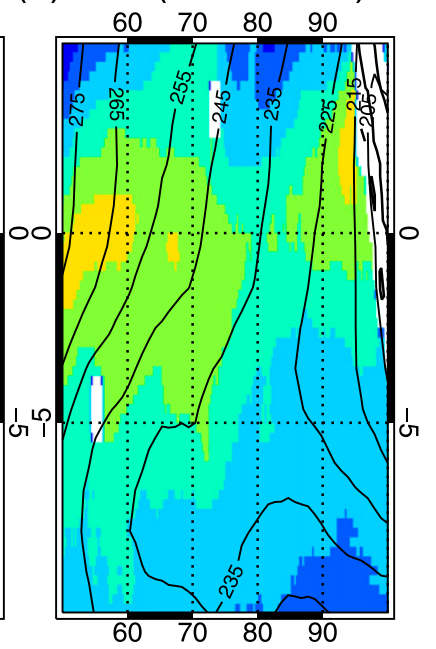

Seaflux dSST (K) averaged by MJO Phase
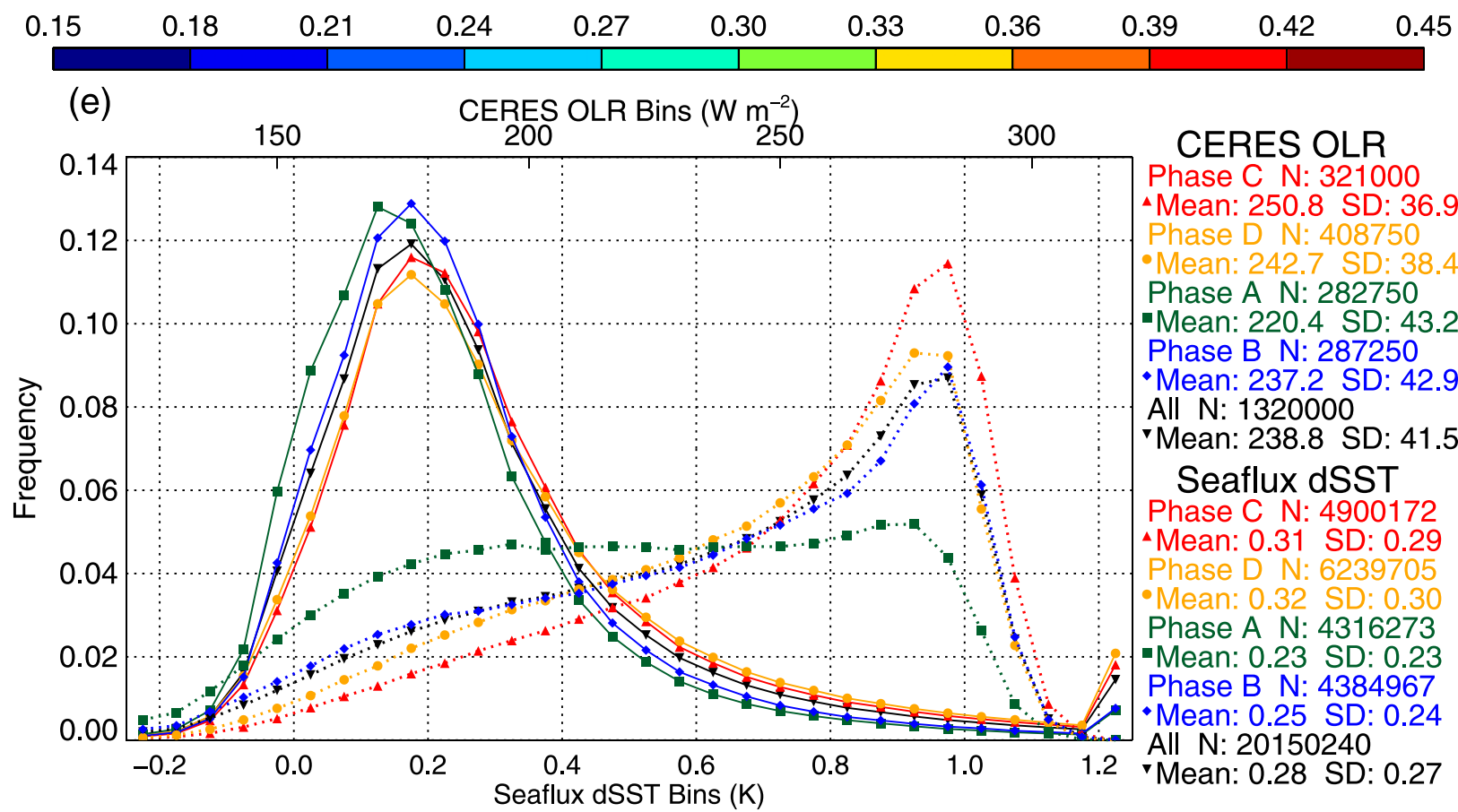

CERES OLR

Phase C N: 321000

${ }^{4}$ Mean: 250.8 SD: 36.9

Phase D N: 408750

-Mean: 242.7 SD: 38.4

Phase A N: 282750

-Mean: 220.4 SD: 43.2

Phase B N: 287250

-Mean: 237.2 SD: 42.9

All N: 1320000

Mean: 238.8 SD: 41.5

Seaflux dSST

Phase C N: 4900172

$\triangle$ Mean: 0.31 SD: 0.29

Phase D N: 6239705

-Mean: 0.32 SD: 0.30

Phase A N: 4316273

Mean: 0.23 SD: 0.23

Phase B N: 4384967

-Mean: 0.25 SD: 0.24

All $\mathrm{N}: 20150240$

Mean: 0.28 SD: 0.27

FIG. 3. SeaFlux dSST and CERES OLR (contours) averaged at each grid box in the study domain by MJO phase: (a) suppressed, (b) transition, (c) active, and (d) all. Shallow coastal or land areas are left blank. (e) Probability density functions binned by 30 bins of daily dSST (solid lines, bottom $x$ axis) and OLR (dashed lines, top $x$ axis) during the suppressed phase (red), transition phase (orange), active phase (green), propagation phase (blue), and all MJO phases (black). The number of samples, mean, and standard deviation for each MJO phase are shown to the right of (e). Valid values beyond the plot range are accumulated in the nearest bin.

this method to plot corresponding diurnal cycle composites of near-surface meteorology and moisture budget terms to gain insight into the subdaily processes driving the anomalies.

Because every grid box in the domain is not necessarily affected by each MJO, future studies should apply a MJO tracking technique using satellite precipitation or OLR similar to Kerns and Chen (2016) in order to exclude grid boxes that remain outside of the convective envelope for each event. We have performed sensitivity experiments on the choice of domain size, revealing an enhanced radiative and moistening response to dSST over a small domain centered on the equatorial central Indian Ocean, but conclusions were generally unchanged.

\section{2) DIURNAL COMPOSITES BY DSST PERCENTILE BIN}

For the second method, we track every local mean day during the suppressed phase across the domain when compositing 
fluxes and clouds. Variables are binned by conditioning days on the strength of the dSST warming by defining four percentile bins in $25 \%$ increments separately for each suppressed MJO event. This method is applied to every daily sample to preserve the diurnal process response to DWLs.

Following the methodology of Taylor $(2012,2014)$, we average each subdaily interval within a particular MJO suppressed phase and dSST bin to examine the composite diurnal cycle characteristics (mean, amplitude, and phase) over the entire region for cloud cover and vertical profiles of all-sky and clear-sky net heating rates from 1-hourly fluxes on pressure levels from CERES SYN Ed4A (CERES Science Team 2015).

\section{Results}

\section{a. Ship and satellite comparison during DYNAMO}

The MJO phase identification as described in the previous section is compared to the identification of the October and November MJO events (hereafter MJO-1 and MJO-2, respectively) during DYNAMO. Using the sounding arrays, Ruppert and Johnson (2015) classified the two MJO events into three phases: suppressed, bottom-heavy active, and topheavy active. The transition from suppressed to active phase (identified as MJO onset in their study) is delineated by the transition from column-integrated drying to moistening. The phase string above Fig. 4 qualitatively matches the transition from drying to moistening as observed in the increase in the PW and RH time series coinciding with the start of the transition phase (Fig. 4a). Table 1 indicates the periods associated with MJO-1 and MJO-2 identified by Ruppert and Johnson (2015) as well as the C, D, and A phases identified by our methodology. Table 1 shows that the dates match well with only 1-3 days separating the exact transition dates. This overlap is made more remarkable by taking into account the more local nature of the identification by Ruppert and Johnson (2015) using sounding observations over a small subset of the Indian Ocean domain versus using the large-scale signatures of OLR anomalies in this study. That is, an exact correspondence is not expected. These results support the interpretation of a CDA cycle as capturing the transition from suppressed to active conditions.

MJO-1 (October 2011) begins with decreasing PW, CAPE, and $P$ followed by tropospheric drying through 10 October (Figs. 4a,d). As the suppressed phase evolves, the SST, T, and surface LW NET increase (Figs. 4b,e) with notable dSST warming in both the suppressed and transition phases (1015 October). Shallow convection begins at the start of the transition phase (11 October), accompanied by column moistening $(d \mathrm{PW} / d t)>0$, increases in CAPE, $q$, and $P$ and reductions in surface LW NET and $T$ (Figs. 4a,b,d,e). Throughout the active phase (21-30 October), SST, $T$, and the surface LW NET decrease while $V, P$, and LHF increase.

MJO-2 (November 2011) reveals much stronger dSST warming during the suppressed phase (10-15 November; Fig. 4b), which aligns with stronger diurnal peaks of CAPE and shallow convection than the previous MJO suppressed phase with weaker dSST. Compared to MJO-1, MJO-2 progresses into relatively more frequent and intense precipitation with increased (reduced) column moistening, LHF, and $V$ (surface LW NET, SST, and $T$ ) during the active phase (20-30 November) (Fig. 4).

SeaFlux SST resolves the diurnal variability observed by the sea snake thermistor $(r=0.8)$ despite the differing resolution. CERES Ed4A surface LW UP relies on daily-averaged SST inputs and therefore does not resolve the $5-10 \mathrm{~W} \mathrm{~m}^{-2}$ diurnal variations observed by the $\mathrm{R} / \mathrm{V}$ radiometer (Fig. 4e). However, the evolution of CERES observed clear-sky OLR corroborates the surface warming observed by R/V Revelle throughout the suppressed phase of MJO-1 (1-10 October). Rapid OLR declines often coincide with large IMERG $P$ events (Fig. 4d). We find the highest correlation between the R/V and SeaFlux $V$ $(r=0.88)$ and LHF estimates $(r=0.77)$. Thermodynamic variables (e.g., $T, q$, and $P$ ) are moderately correlated $(r=0.54$, $r=0.56$, and $r=0.44$, respectively).

\section{b. Satellite results}

The satellite dataset captures the evolution of the key features of the MJO events and in particular the changes in conditions during the suppressed to active transition. With this confidence in the satellite dataset, we composite over $44 \mathrm{MJO}$ events to investigate the preferential impacts of stronger versus weaker diurnal warming across a range of events. As Fig. 4 shows, there is a spectrum of diurnal warming occurring under suppressed conditions across two MJO events even at approximately the same location several weeks apart.

Applying the first method of compositing [section 3b(1)], we examine the anomalous evolution of SeaFlux SST, CERES clear-sky OLR, SeaFlux $V$, and SeaFlux $q$ over 29 days of the composite MJO cycle. SST anomalies remain slightly negative (positive) during the MJO cycle over grid box locations within the lowest (highest) 50th percentile of event-relative dSST strength (Fig. 5a). The top 25th percentile of dSST locations show $0.5 \mathrm{~K}$ anomalous SST occurring the day before the start of the transition phase, noted as the bottom-heavy active phase by Ruppert and Johnson (2015), thus providing evidence that locations with DWLs tend to warm SST via local oceanatmosphere coupling (Fig. 5a). These SST anomalies remain elevated as do the absolute SST (not shown) in a manner consistent with modeling results from Bernie et al. (2008) that show the DWL rectification onto higher total SST.

For the three highest-dSST bins, clear-sky OLR anomalies maximize before the start of the transition phase and decrease rapidly during the transition phase, becoming negative during the active phase (Fig. 5b). Anomalies flip from 1 to $2 \mathrm{~W} \mathrm{~m}^{-2}$ at the end of the suppressed phase to between -1 and $-2 \mathrm{~W} \mathrm{~m}^{-2}$ during the active phase over DWL locations although event-toevent variability (and sampling error) is large as shown by the standard error bars (Fig. 5b).

The $V$ anomalies show the opposite behavior, remaining positive (negative) for the bottom (top) 50th percentile of dSST (Fig. 5c). Interestingly, the rate of change in anomalous $V$ rapidly decreases (increases) at the start of the transition phase in the lowest-(highest-) dSST regime (Fig. 5c). Near-surface specific humidity exhibits more consistent behavior; all bins show a transition from negative anomalies to positive 
(a)

R/V Revelle Ship Track Oct 1 - Dec 7, 2011

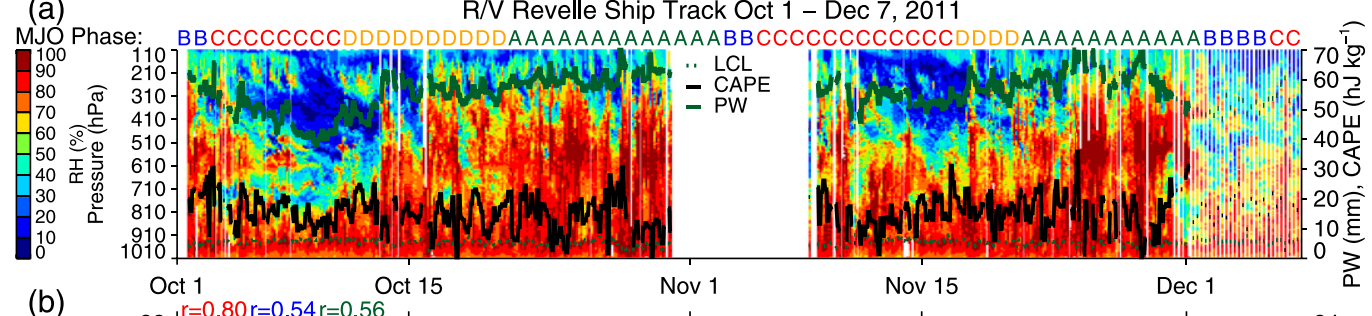

(b)

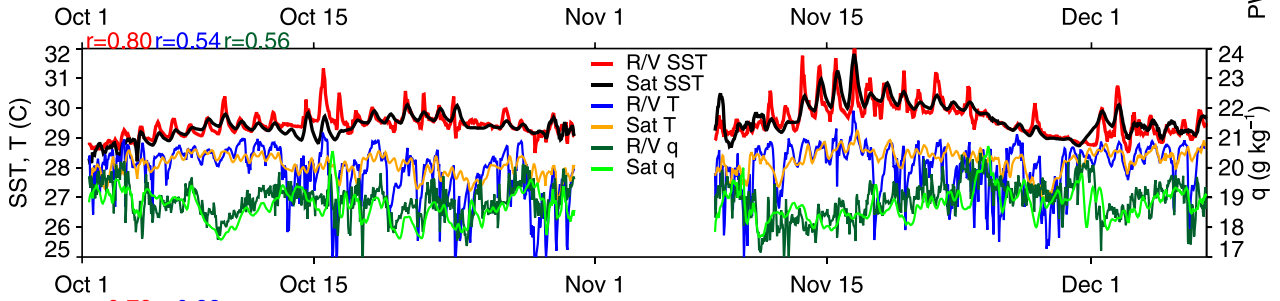

(c)

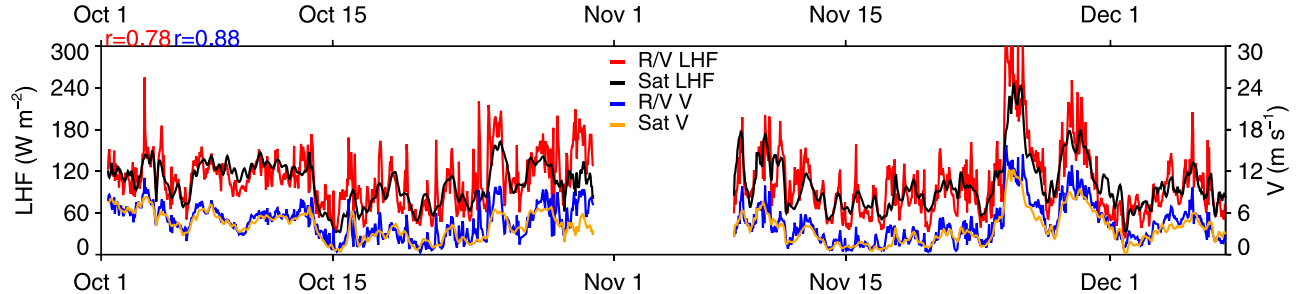

(d)

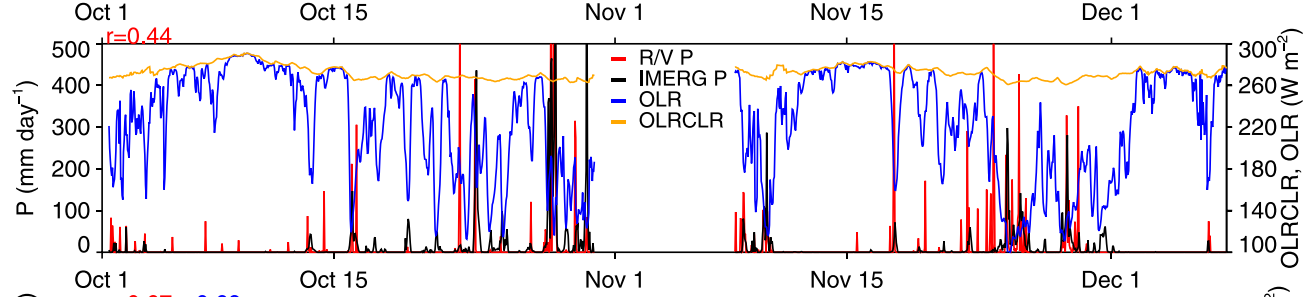

(e)

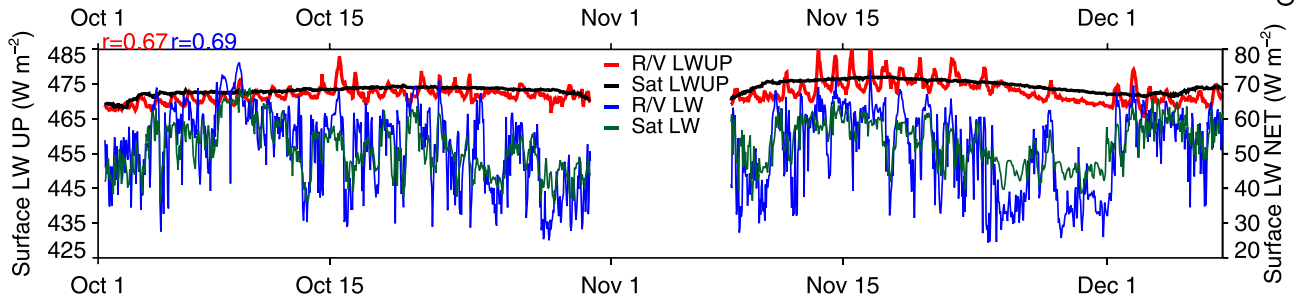

FIG. 4. DYNAMO R/V Revelle observations over two complete MJO events (see phase string evolution at top) between 1 Oct and 7 Dec 2011 compared and correlated against corresponding satellite measurements when applicable. (a) Time-height plot of 3-hourly radiosonde (level 4; $5 \mathrm{hPa}$ gridded) relative humidity (with respect to ice when below freezing) between the surface and $110 \mathrm{hPa}$ (shaded), the lifted condensation level (dashed green line; $\mathrm{hPa}$ ); right axis: PW (green line; $\mathrm{mm}$ ) and CAPE (black line; $\mathrm{hJ} \mathrm{kg}^{-1}$ ). White lines represent bad or missing data. (b) Hourly sea snake SST (red), SeaFlux SST (black line), ship 2-m temperature (blue line), SeaFlux near-surface temperature (orange line); right axis: ship 2-m specific humidity (dark green line) and SeaFlux near-surface specific humidity (light green line). (c) Ship latent heat flux (red line) and SeaFlux latent heat flux (black line); right axis: ship 10-m wind speed (blue line) and SeaFlux near-surface wind speed (orange line). (d) Ship-observed precipitation rate (red line) and IMERG precipitation rate (black line); right axis: CERES OLR (blue) and CERES clearsky OLR (orange). (e) Ship radiometer surface LW up (red line) and CERES surface LW up (black line); right axis: ship radiometer surface LW net (blue line) and CERES surface LW net (dark green line). Correlation coefficients $(p<0.05)$ between each variable pair are located at the top left of each plot when applicable.

anomalies throughout the MJO cycle in tandem with the largescale atmosphere drying to moistening from suppressed to active phases. This negative to positive $q$ change is strongest over the highest dSST locations due to the larger contrast between clear conditions during the first 14 days and deep convection following the suppressed phase (Fig. 5d).

The SeaFlux SST diurnal cycle shows increasing diurnal amplitude and local day averages for each higher-dSST bin
(Fig. 6a). Consistent with other studies (e.g., Thompson et al. 2019), the inverse relation between dSST and $V$ is the most robust and is related to the suppression of ocean mixing that encourages warm layer development with weaker winds. Last, $q$ varies weakly by dSST due to its codependence on both $T$ and LHF, which vary oppositely with dSST. These results indicate that high-dSST regions exhibit systematically different evolutions in their diurnal cycle and in their anomalous evolution 
TABLE 1. Dates of MJO-1 and MJO-2 events during DYNAMO as determined by Ruppert and Johnson (2015) and methodology employed in this study (boldface).

\begin{tabular}{cccc}
\hline \hline Event & Suppressed $(\mathrm{C})$ & Bottom-heavy active (D) & Top-heavy active $(\mathrm{A})$ \\
\hline MJO-1 & $1-13$ Oct & $14-19$ Oct & 20 Oct-4 Nov \\
& $\mathbf{1 - 1 0}$ Oct & $\mathbf{1 1 - 2 0 ~ O c t ~}$ & $\mathbf{2 1}$ Oct-1 Nov \\
MJO-2 & $10-16$ Nov & $17-21$ Nov -30 Nov \\
& $\mathbf{6 - 1 5}$ Nov & $\mathbf{1 6 - 2 0}$ Nov & $\mathbf{2 1}$ Nov-1 Dec \\
\hline
\end{tabular}

leading up to the transition from the suppressed to active phase than low-dSST regions. This result suggests that high- (low-) dSST regions contribute to a "building up" (reduction) of SST and near-surface temperature throughout the suppressed phase, thus influencing MJO initiation.

\section{c. Moisture budget sensitivity to dSST}

In the following section, we compare and contrast relationships between observed DWL locations during the suppressed MJO and the moisture budget using observations, ERA5, and MERRA-2. The local moisture budget is shown below in Eq. (3):

$$
E-P-\mathrm{MFD}=(d W / d t)+\boldsymbol{\varepsilon} ;
$$

$(d W / d t)+\varepsilon$ is the local column-integrated moisture tendency along with a residual term due to errors in dynamics or physics (Brown and Kummerow 2014). We examine the difference between the assimilated moisture tendency and the sum of the forecast model moisture budget terms at each local hour for both reanalyses separately as summarized below in Eq. (4):

$$
\{\boldsymbol{\varepsilon}(h)=24 \times[\mathrm{PW}(h)-\mathrm{PW}(h-1)]-[E(h)-P(h)-\mathrm{MFD}(h)]\}_{h=0,23}
$$

Daily Anomalous Evolution -14 to 14 days since start of D

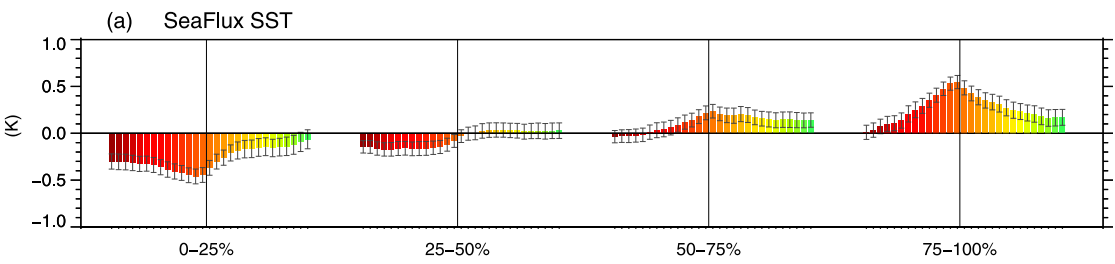

(b) CERES OLRCLR
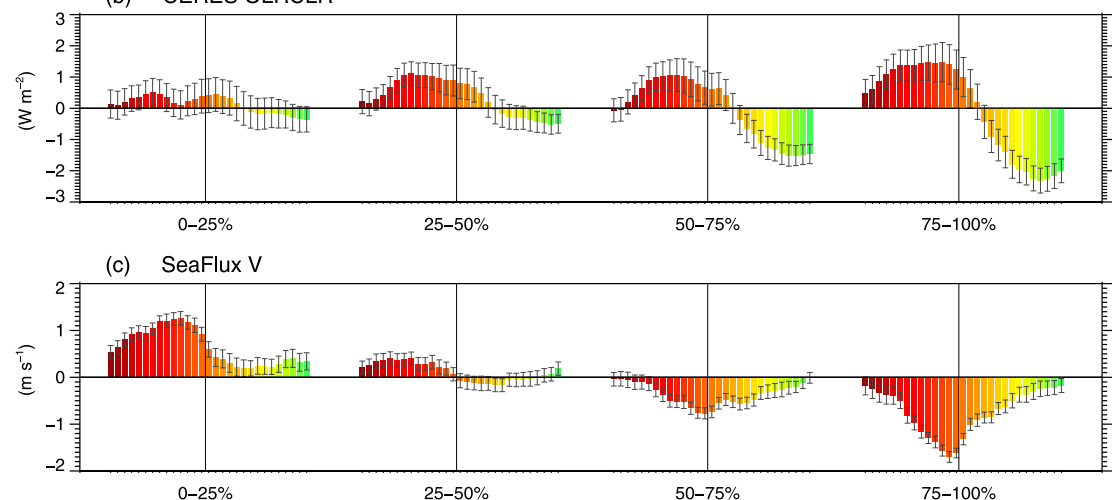

(d) SeaFlux q

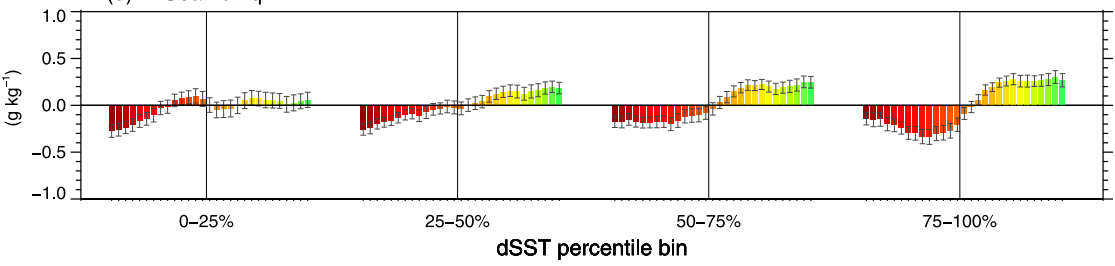

FIG. 5. The anomalous evolution of (a) SeaFlux SST, (b) CERES clear-sky OLR, (c) SeaFlux near-surface wind speed, and (d) SeaFlux near-surface specific humidity composited by dSST percentile bins (left to right columns) 14 days before and after the start of the transition phase (vertical black line). Colors represent approximate MJO phase color from Fig. 2. Standard errors are displayed as error bars. 
(a)

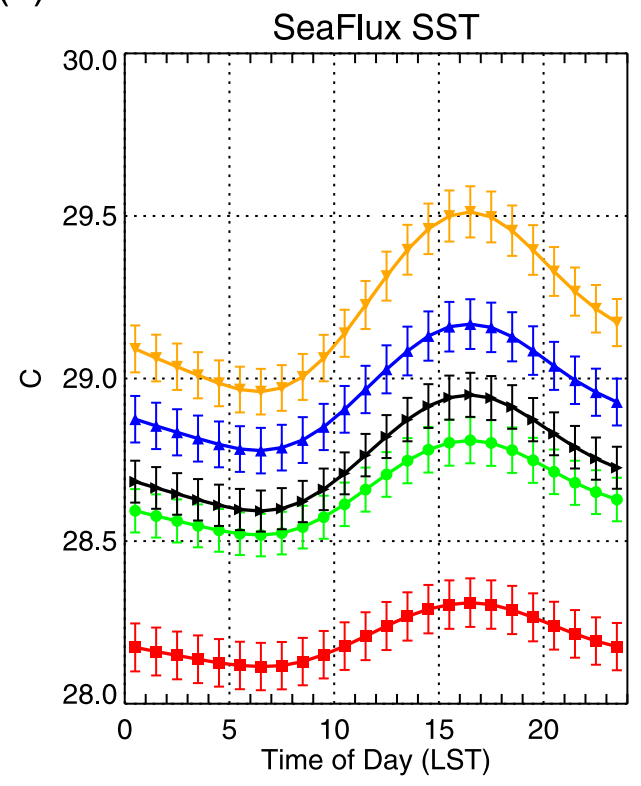

(b)

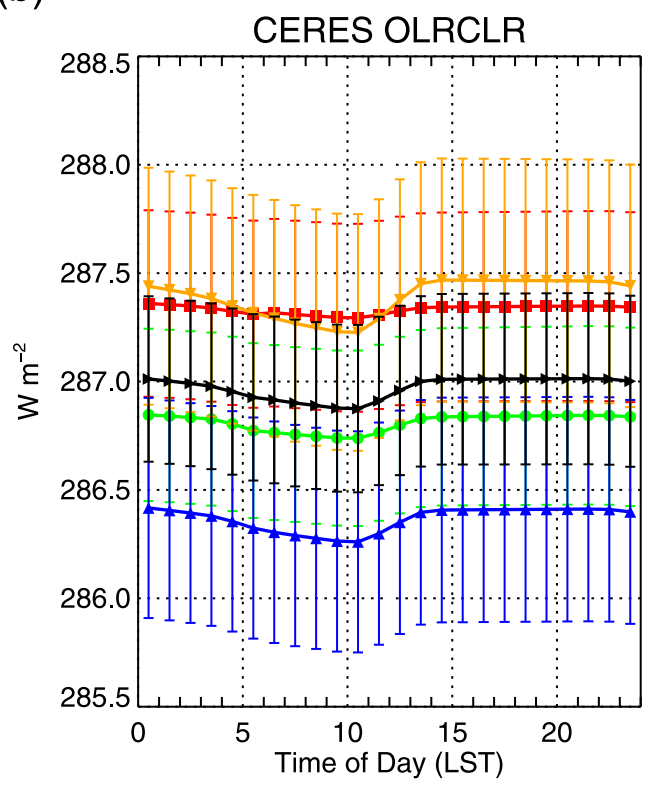

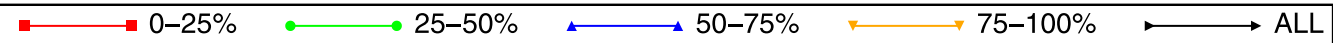

(c)

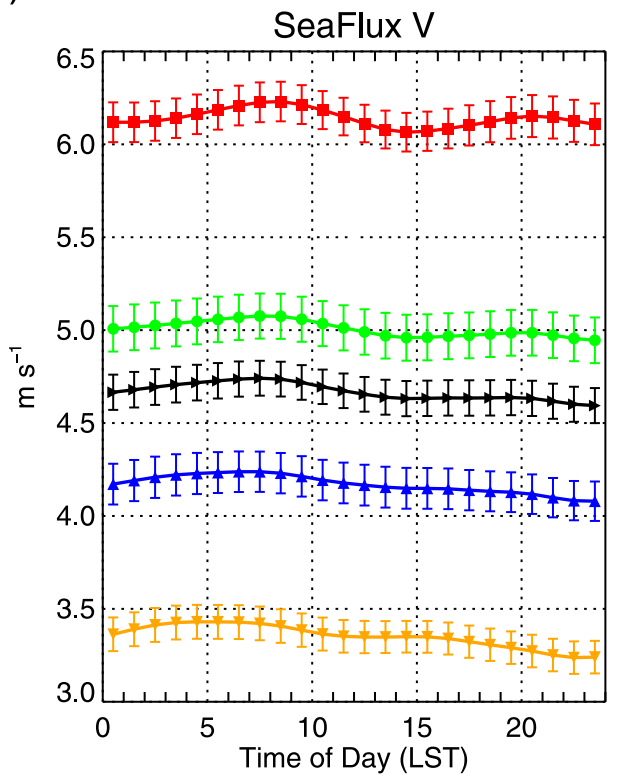

(d)

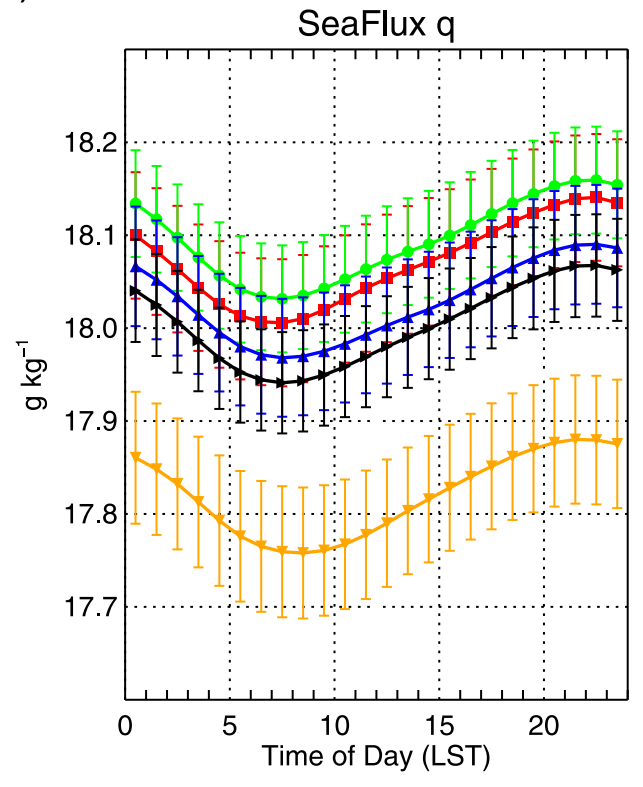

\section{Phase C composites over: [10S - 5N; $50-100 E]$}

FIG. 6. The suppressed phase diurnal cycle composited by dSST percentiles: 0th-25th (red line), 25th-50th (green line), 50th-75th (blue line), 75th-100th (orange line), and 0th-100th (black line) of variables from Fig. 5. Standard errors are displayed as error bars.

to quantify the error of the forecast model relative to the data assimilation scheme. Further, we compare the sensitivity of diurnal composites and the anomalous evolution of moisture budget terms and residuals to dSST using observed $E$ and $P$ to investigate the subdaily processes driving moistening or drying in observations and models.

The observed $P$ diurnal maximum occurs between 0400 and 0800 LST for all dSST bins (Fig. 7a), highlighting the early 


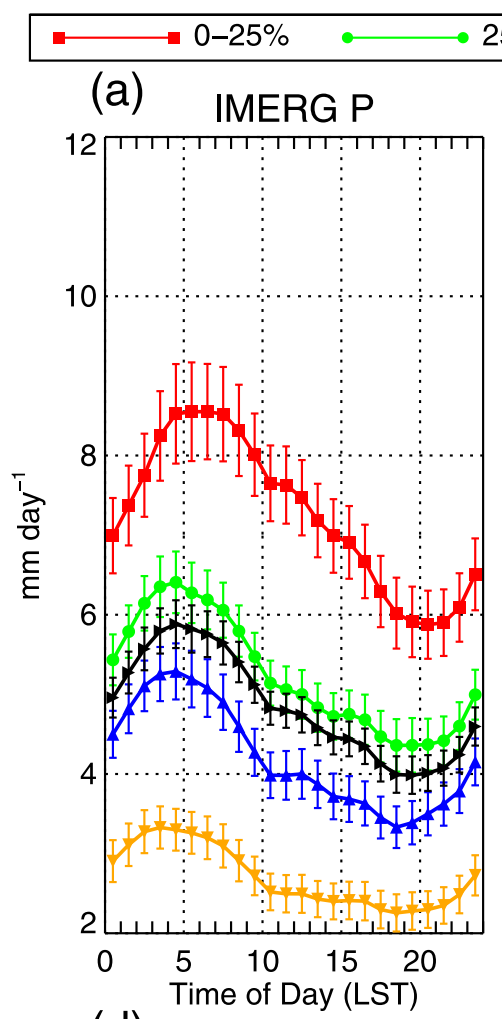

(d) SeaFlux E

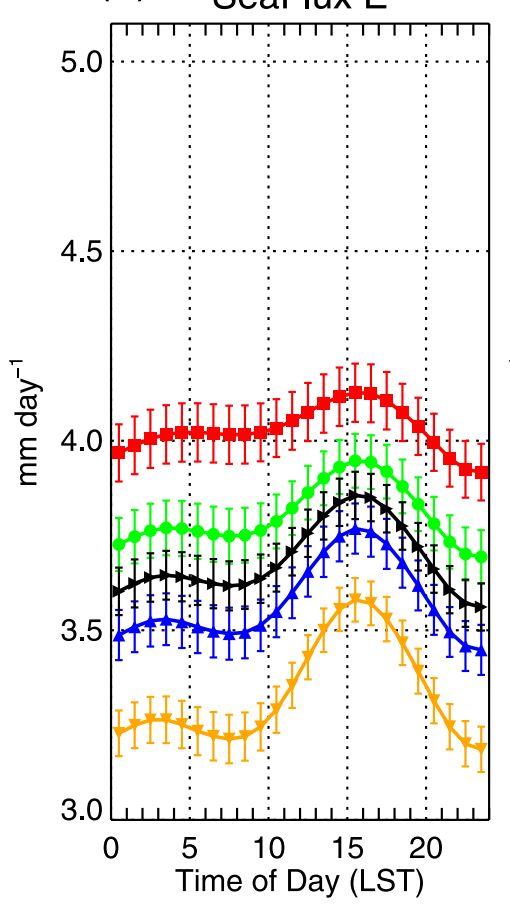

Phase C compo

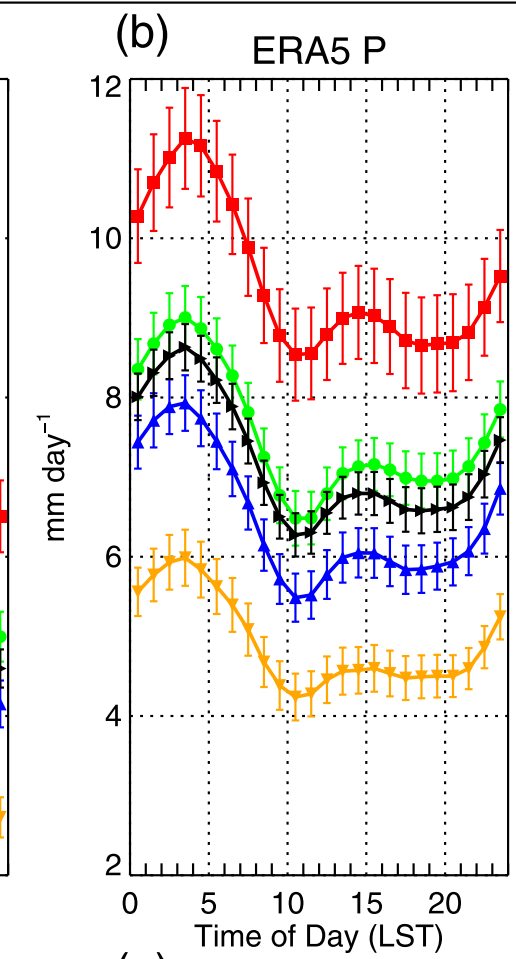

(e) ERA5 E

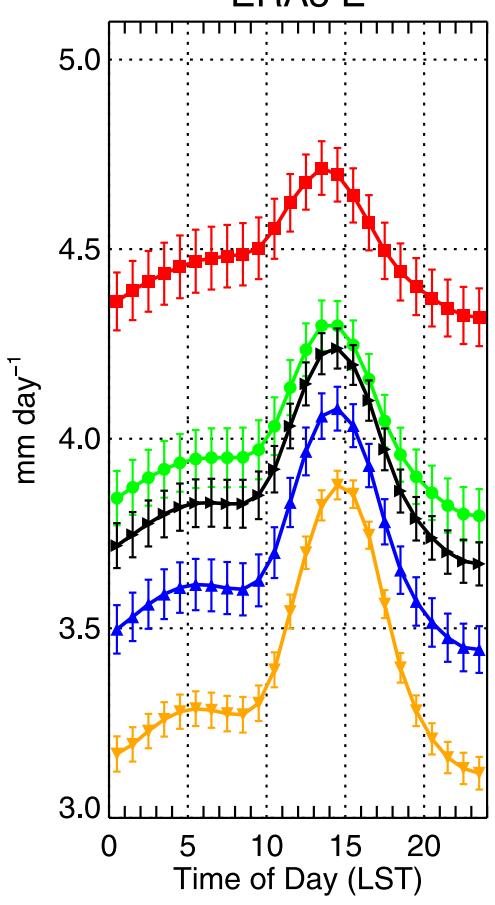

(c) MERRA-2 P

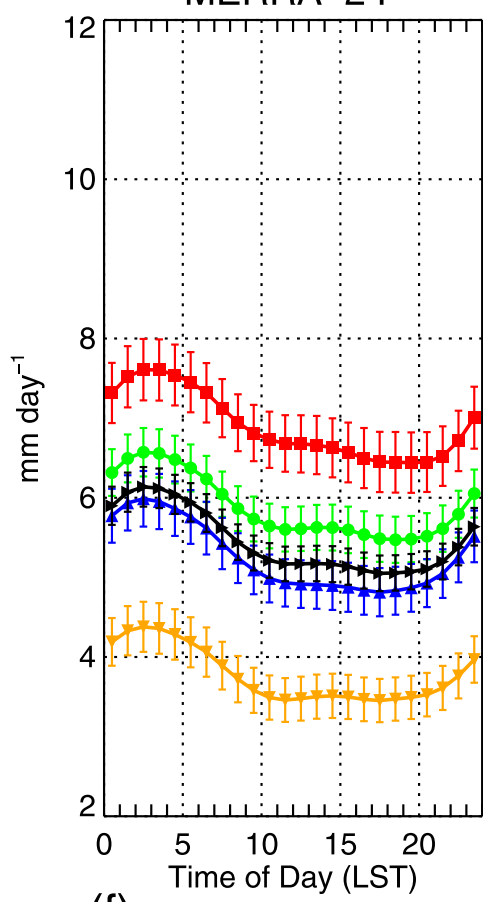

(f)

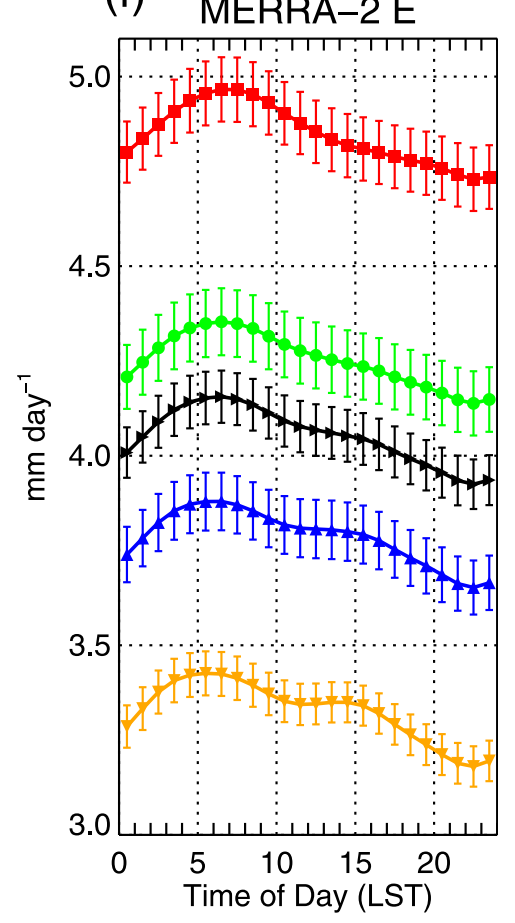

FIG. 7. The suppressed phase diurnal cycle composited by dSST percentiles: 0th-25th (red line), 25th-50th (green line), 50th-75th (blue line), 75th-100th (orange line), and 0th-100th (black line) of (a) IMERG $P$, (b) ERA5 $P$, (c) MERRA-2 $P$, (d) SeaFlux E, (e) ERA5 E, and (f) MERRA-2 E. Standard errors are displayed as error bars. 
morning preference for deep convection over tropical oceans. Note that $P$ decreases throughout the day for all bins, minimizing between 1800 and 2200 LST. The strongest DWL locations receive $\sim 3$ times reduced $P$ (orange line, Fig. 7 a) than the weakest DWL locations (red line, Fig. 7a) during midmorning and late afternoon, coincident with unfavorable conditions for deep convection under large-scale subsidence and clearer skies. The reanalyses capture general features of the observed $P$ diurnal cycle and its sensitivity to DWL percentile; however, differences exceed $30 \%-50 \%$ for both ERA5 (Fig. 7b) and MERRA-2 (Fig. 7c) relative to IMERG (Fig. 7a). Both models produce too much $P$ over areas of the strongest observed DWLs and vary too little over the dSST regimes (Figs. 7b,c). ERA5 produces excessive $P$ during the suppressed MJO at all times of day (Fig. 7b), especially overnight, maximizing several hours earlier than IMERG; however, ERA5 varies similarly in magnitude over the diurnal cycle and across MJO events compared to IMERG, suggesting that ERA5 better captures diurnal processes related to air-sea coupling (Figs. 7a-c). Despite the weaker diurnal amplitude and reduced sensitivity to dSST regime than observed, MERRA-2 reveals better absolute agreement with IMERG when averaged over the suppressed MJO (black lines, Figs. 7a-c).

The composite $E$ diurnal cycle (Figs. 7d-f) shows a weaker dependence on dSST than $P$ (Figs. 7a-c): $E$ changes by $\sim 1 \mathrm{~mm} \mathrm{day}^{-1}$ from the lowest to the highest dSST regime, contrasting with the $\sim 5 \mathrm{~mm} \mathrm{day}^{-1} P$ reductions found over areas of stronger diurnal warming. The composite SeaFlux diurnal $E$ amplitude is nearly twice as large over DWL locations (Fig. 7d). Using ERA5, the composite diurnal $E$ amplitude increases more strongly than SeaFlux over DWLs (orange and blue lines, Fig. 7e). MERRA-2 E maximizes in the early morning (Fig. 7f), $12 \mathrm{~h}$ earlier than SeaFlux (Fig. 7d). Consistent with wet early morning biases (Figs. 7a-c), nocturnal $E$ is $10 \%-$ $25 \%$ greater than SeaFlux and $E$ is overly sensitive to dSST location in both models (Figs. 7d-f).

Anomalous $P$ maximizes toward the end of the 29-day cycle for all dSST bins, and the highest-dSST bin experiences the largest anomalous $P$ fluctuations throughout the MJO cycle (Figs. 8a-c). Persistent convective $P$ during the suppressed MJO in ERA5 (Fig. 7b) skews the distribution toward positive values, especially over the weakest dSST locations (Fig. 8b). Similar to Fig. 7, MERRA-2 anomalous $P$ evolution agrees more closely with IMERG across the composite MJO cycle (Figs. 8a-c). Despite the positively shifted ERA5 $P$ anomalies, their relative sensitivity to dSST is larger than MERRA-2 over the MJO cycle, better matching the observed sensitivity. Anomalous $E$ varies relatively weakly over the $\mathrm{MJO}$ cycle in both models and observations (Figs. 8d-f). ERA5 matches the observed evolution more closely than MERRA-2, which slightly overestimates $E$ variability for every dSST regime (Figs. 8d-f). For both $E$ and $P$, the largest differences occur over DWL locations at the end of the suppressed MJO due to insufficient anomalous drying in MERRA-2, potentially pointing to the lack of air-sea coupling within GEOS-5 parameterizations (Molod et al. 2015) or the lower spatial resolution of MERRA-2 (Table 2).
Combining satellite-observed $E$ and $P$ with MFD from each reanalysis, we estimate the suppressed phase average moistening rate (plus errors in the model dynamics and MW sampling) at each hour as a residual (Fig. 9). Over all ocean points, moistening rates generally increase during the day and decrease overnight, remaining near 0 or positive for all hour boxes after sunrise (black line, Figs. 9a,b). The greatest residual moistening rate occurs in the late afternoon $(\sim 1800$ LST) and shows a strong dependence on dSST regime (orange and blue lines, Figs. 9a,b). For the lowest-dSST bin, the moistening rate maximizes around $2 \mathrm{~mm} \mathrm{day}^{-1}$ at $2000 \mathrm{LST}$ (red line, Figs. 9a,b) due to reduced afternoon precipitation (Fig. 7a) representing a nearly $50 \%$ reduction relative to DWL locations for both models (Figs. 9a,b).

Considering the large diurnal $E$ and $P$ biases compared to observations (Fig. 7), the MFD diurnal cycle likely has significant uncertainty. Therefore, we also use hourly moisture tendency from ERA5 (Fig. 9c) and MERRA-2 (Fig. 9d) to evaluate the moisture budget closure. Somewhat surprisingly, very good agreement is found in Figs. 9a-d. Both reanalyses show sharp early morning drying before rapidly recovering to slight moistening by midmorning (black lines, Figs. 9c,d). The greatest moistening rate $\left(\sim 3 \mathrm{~mm} \mathrm{day}^{-1}\right)$ occurs between 1600 1900 LST over DWL locations (Figs. 9a,b) coinciding with diurnal minimum $P$ (Fig. 7a) and diurnal maximum $E$ (Fig. 7d). These findings apply to both approaches of quantifying the moistening rate. The lowest dSST regime shows $\sim 30 \%$ reduced moistening during late afternoon (Figs. 9c,d). Small hourly differences between the satellite-model moistening residual and the corresponding moisture tendency suggest good agreement between the model dynamics and observed physics. Satellite $E$ and $P$ better constrain the dynamics within ERA5 (MERRA-2) during the late afternoon (early morning). During these times, each model produces too much $P$ compared to IMERG (Figs. 7a-c), resulting in a positive bias for both satellite-model moistening residuals (Figs. 9a,b) as a result of strong moisture flux convergence within the models that is unbalanced by the observed physics (shown later).

The evolution of anomalous moistening over the MJO cycle (suppressed-transition-active) reveals distinct characteristics by dSST bin (Fig. 10). The satellite-model moistening residual increases throughout the first 14 days of the MJO cycle for DWL locations and remains elevated throughout the first 3-5 days of the transition phase ranging between 1.5 and $2.5 \mathrm{~mm} \mathrm{day}^{-1}$ (Figs. 10a,b). The anomalous moisture tendency varies similarly over the MJO cycle with significantly dampened variability (Figs. 10c,d). Over DWL locations, the anomalous moisture tendency increases over the last $\sim 5$ days of the suppressed phase, maximizing between 1 and $2 \mathrm{~mm} \mathrm{day}^{-1}$ at the end of the suppressed phase for ERA5 and MERRA-2 (Figs. 10c,d).

Rearranging Eq. (3), we also solve for MFD as the residual by summing SeaFlux $E$ - IMERG $P$ - moisture tendency using both ERA5 (Fig. 11a) and MERRA-2 (Fig. 11b). The sampling $\varepsilon$ attached to these MFD residuals should be significantly less than the satellite-model moistening rate residuals from Figs. 9 and 10, which contain errors from both the forecast model and satellite sampling. ERA5 reveals bimodal MFD 


\section{Daily Anomalous Evolution -14 to 14 days since start of $D$}

(a) IMERG P

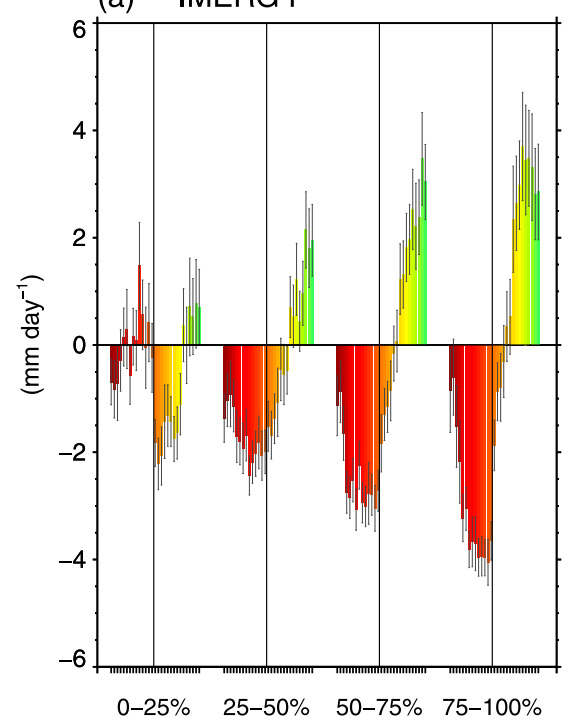

(d) SeaFlux E

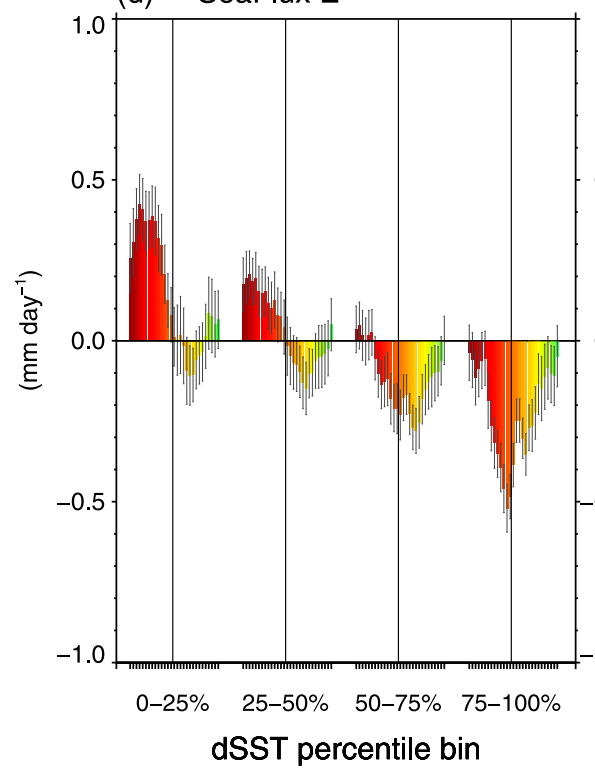

(b) ERA5 P

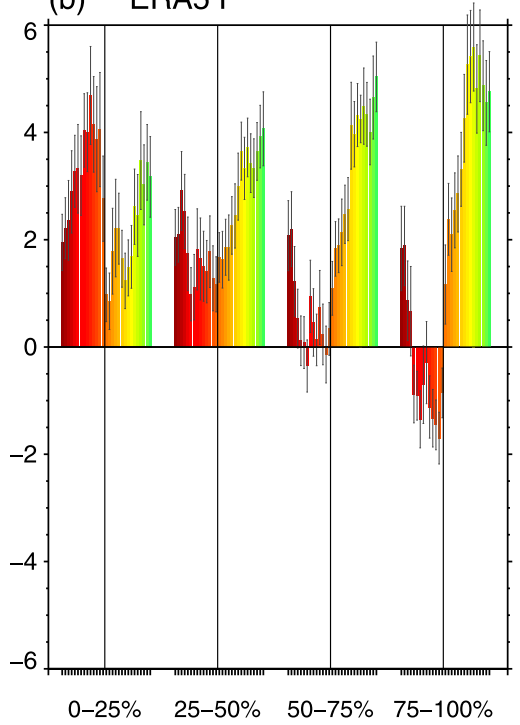

(e) ERA5 E

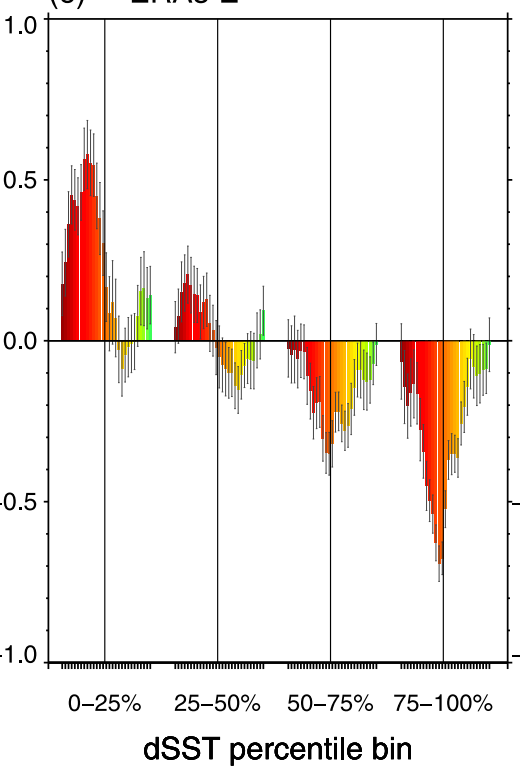

(c) MERRA-2 P

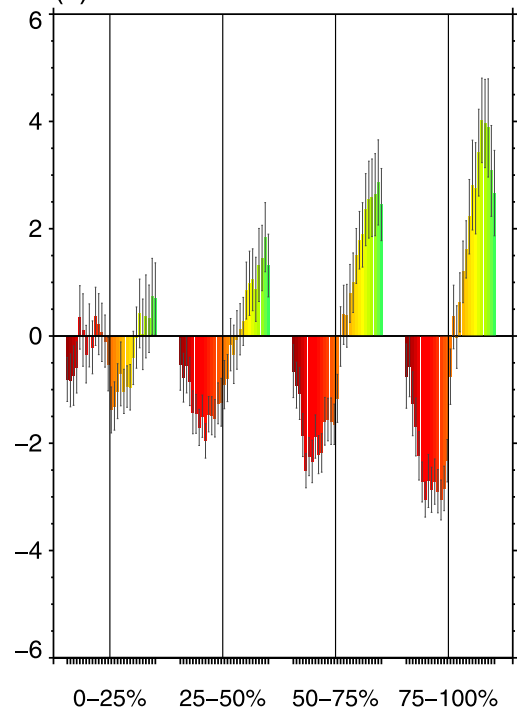

(f) MERRA-2 E

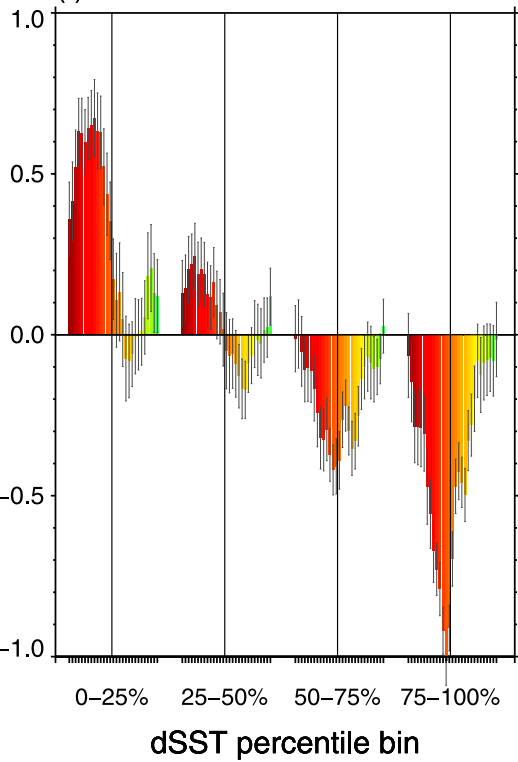

FIG. 8. The anomalous evolution of the variables from Fig. 7 composited by dSST percentile bins (left to right columns) 14 days before and after the start of the transition phase (vertical black line). Colors represent approximate MJO phase color from Fig. 2. Standard errors are displayed as error bars.

minima (Fig. 11a) occurring during early morning (associated with maximum IMERG $P$ ) over weak DWL locations and in the late afternoon over strong DWL locations where MFD decreases throughout the day without resulting in a late afternoon $P$ maximum, thus moistening the column. MERRA-2 MFD residuals show similar bimodal minima and sensitivity to dSST percentile (Fig. 11b).

The large ERA5 $P$ during the early morning (Fig. 7b) is balanced by net moisture convergence in the model across all dSST bins except for a period of weak morning MFD over the highest-dSST bin (orange line, Fig. 11c). The late afternoon moistening maximum (Figs. 9c,d) aligns with developing moisture convergence (Figs. 11c,d), local moistening (Fig. 7e), and diurnal minimum $P$ (Figs. $7 \mathrm{~b}, \mathrm{c})$. Areas with the strongest diurnal warming also exhibit a marked transition from moisture divergence early in the day to moisture convergence in the late afternoon (Figs. 11c,d) without a late afternoon $P$ increase, thus moistening the column.

Residual MFD anomalies reveal an additional $1-2 \mathrm{~mm}_{\text {day }}{ }^{-1}$ of anomalous divergence during the suppressed $\mathrm{MJO}$ and a slower transition to negative MFD anomalies at the start of the 
TABLE 2. Summary of observations and model products.

\begin{tabular}{llll}
\hline \multicolumn{1}{c}{ Dataset } & \multicolumn{1}{c}{ Spatial resolution } & \multicolumn{1}{c}{ Frequency } & \multicolumn{1}{c}{ Variables } \\
\hline SeaFlux v3 & $0.25^{\circ} \times 0.25^{\circ}$ & Hourly & SST, LHF, SHF, $q, T, V$ \\
CERES Ed. 4A & $1^{\circ} \times 1^{\circ}$ & Hourly & $\begin{array}{c}\text { OLR, OLRCLR, TCC, HCC, MCC, } \\
\text { LCC, surface and in-atmosphere } \\
\text { fluxes }\end{array}$ \\
& & & $P$ \\
IMERG v06 & Gridded to $0.25^{\circ} \times 0.25^{\circ}$ & Hourly averaged & SST, LHF, $P$, surface longwave fluxes, \\
R/V Revelle surface & Ship-track point measurement & Hourly averaged & $q, T, V$ \\
R/V Revelle upper air & 5 -hPa bins from surface to & 3-hourly during intensive & RH, CAPE, LCL, PW, $V$ \\
& $100 \mathrm{hPa}$ & observation periods & MFD, PW, $P, E$ \\
ERA5 & $0.25^{\circ} \times 0.25^{\circ}$ & Hourly & MFD, PW, $P, E$ \\
MERRA-2 & $0.625^{\circ} \times 0.5^{\circ}$ & Hourly &
\end{tabular}

transition phase (Figs. 12a,b) compared to the reanalyses (Figs. 12c,d). The evolution of ERA5 MFD anomalies (Fig. 12c) closely agrees with MERRA-2 (Fig. 12d). Anomalous MFD decreases rapidly $\left(3-4 \mathrm{~mm} \mathrm{day}^{-1}\right.$ ) over the final $48 \mathrm{~h}$ of the suppressed phase for both reanalyses suggesting that a change in large-scale dynamics is the primary driver for moistening the pre-MJO environment over DWLs. However, when computed as a residual, changes in large-scale dynamics are a less significant driver of column moistening at the end of the suppressed phase. This result supports that the role of local air-sea coupling on moistening the suppressed MJO environment over DWLs is underestimated in both MERRA-2 and ERA5.

\section{d. Observed cloud and radiative covariation with DWL strength}

When combined with insights from the previous sections, the cloud cover diurnal cycle composited by dSST bin reveals important clues on the scale and source of persistent instabilities that impact the suppressed phase radiation budget. We apply the diurnal compositing approach [section $3 \mathrm{~b}(2)$ ] to isolate the diurnal radiative response to increasing dSST. Overall, the cloud cover difference between regimes is smallest in the early morning due to frequent high- and midlevel clouds associated with widespread deep convection (Figs. 13a,b). High- and middle-level clouds rapidly decrease between 0200 and 0600 LST for the highest-dSST bins. After sunrise, all dSST bins reveal a rapid increase in low cloud cover (LCC) and high cloud cover (HCC) associated with the maximum precipitation rate (Fig. 7a) followed by several hours of rapid clearing through 1000 LST (Figs. 13a,c).

The composite LCC diurnal cycle reveals bimodal maxima occurring near sunrise and late afternoon (Fig. 13c). The lowest-dSST bin shows relatively larger daytime increases in high and middle level clouds (red line, Figs. 13a,b,d), whereas the daytime increase in low clouds dominates the total cloud cover diurnal cycle for the three higher-dSST bins (orange, blue, and green lines; Figs. 13c,d). In contrast to the high- and midlevel cloud fractions that shift dramatically_about a $20 \%$ (10\%) reduction for the high- (mid-) level-from low to high dSST (see Figs. 13a,b), the low cloud fractions are more consistent despite moving from less to more suppressed local conditions. The lack of afternoon precipitation associated with
DWLs (orange line, Fig. 7a) suggests that these clouds act to moisten the lower troposphere as detraining cumuli after sunset and contribute to the stronger column moistening in high-dSST bins compared to low-dSST bins.

Diurnal clear versus cloud radiative heating rate profiles are differenced between extreme-dSST bins (Figs. 14a,b). The clear-sky net heating rates difference between the high- and low-dSST bin are below $0.1 \mathrm{~K}_{\text {day }}{ }^{-1}$ for all times of day at all levels (Fig. 14a). The difference in the cloud net heating rate is much more significant (Fig. 14b). During midday, clouds associated with convective anvils absorb incoming solar radiation and heat the middle and upper troposphere by over $1 \mathrm{~K}$ day $^{-1}$ more in the low-dSST bin than the relatively clear high-dSST bin. Overnight, cloud longwave warming results in about $0.5 \mathrm{~K} \mathrm{day}^{-1}$ additional warming throughout the lower to middle troposphere in the low-dSST bin than the high-dSST bin; however, nocturnal convective cloud-top cooling results in greater cooling in the upper troposphere (reddish colors, Fig. 14b). During midday in the lower troposphere, the cloud net heating rate difference is approximately 0 (Fig. 14b) due to similar low-level cloudiness between dSST bins (Fig. 13c).

The all-sky net effect of radiative heating is dominated by clear-sky longwave cooling for all dSST bins when averaged over the local day, especially over DWLs (Figs. 14c,d). Near the surface, the local day average shortwave heating warms the highest-dSST bin by $0.9 \mathrm{~K}$ day $^{-1}, 0.2-0.3 \mathrm{~K}_{\text {day }}{ }^{-1}$ greater than the lowest bin (not shown). However, the larger cloud cover and humidity in the lowest-dSST bin act in tandem to radiatively warm the lower, middle, and upper levels by an additional $0.4,0.3$, and $0.5 \mathrm{~K} \mathrm{day}^{-1}$, respectively, compared to the highest-dSST bin when averaged over all hours.

When viewed in the context of radiative destabilization, these heating rate differences impact parcel buoyancy and local cloud development. Increased surface shortwave warming coupled with decreased warming at the upper levels from a combination of greater nocturnal longwave cooling and reduced cloud shortwave warming enhance afternoon convective instability in the higher-dSST bins in the low to midtroposphere, supporting cumulus development into the midtroposphere. Conversely, the preferential upper-level warming in the low-dSST bin acts to radiatively stabilize the environmental temperature profile during peak insolation (Fig. 14d). 
(a)

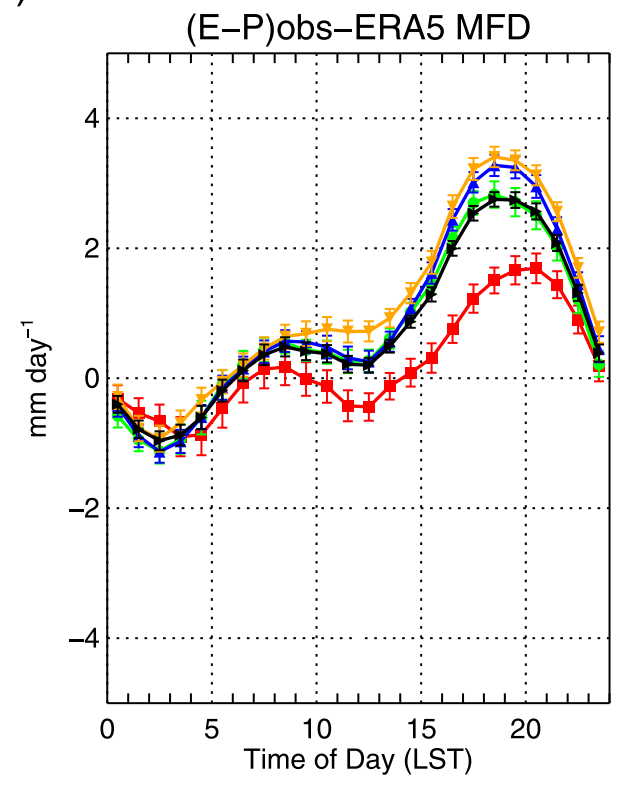

(b)

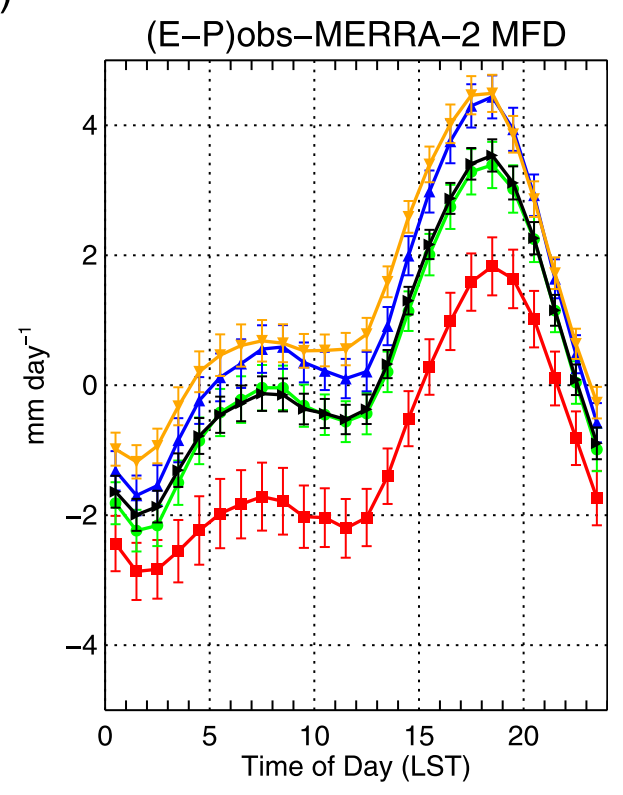

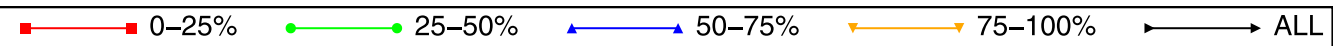

(c)

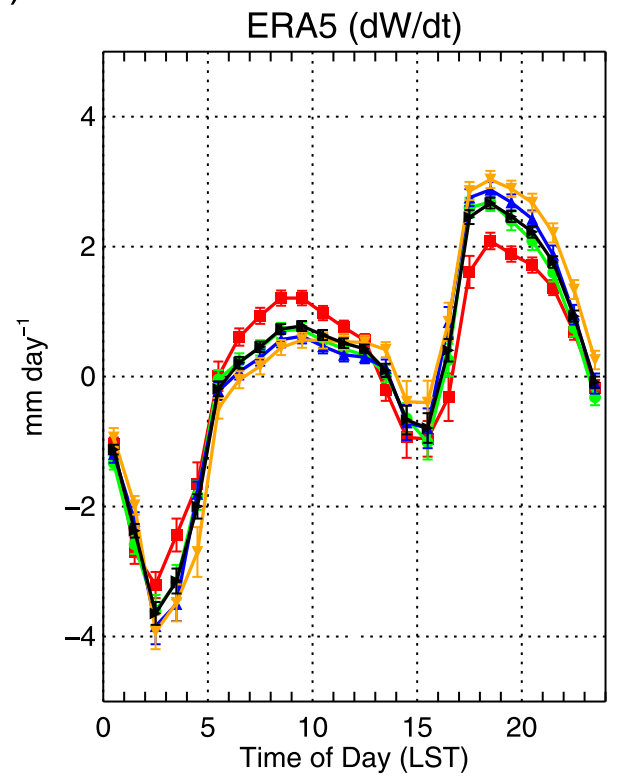

(d)

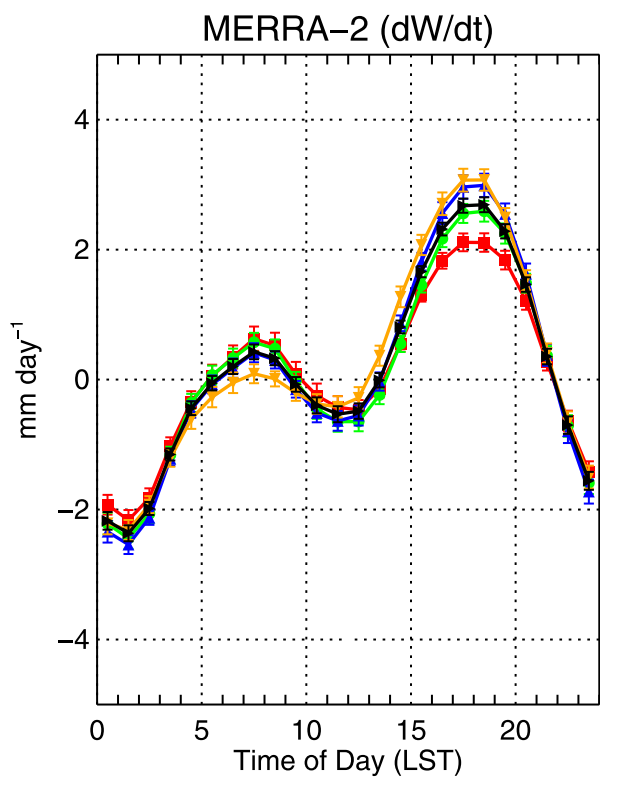

\section{Phase C composites over: [10S - 5N; $50-100 E]$}

FIG. 9. The suppressed phase diurnal cycle composited by dSST percentiles: 0th-25th (red line), 25th-50th (green line), 50th-75th (blue line), 75th-100th (orange line), and 0th-100th (black line) of (a) residual moistening rate using ERA5 MFD, (b) residual moistening rate using MERRA-2 MFD (c) ERA5 moisture tendency, and (d) MERRA-2 moisture tendency. Standard errors are displayed as error bars.

Thus, radiative forcing provides a positive feedback to the hypothesis of local SST-driven generation of convective instability (Fig. 4a), which could lead to ventilation of nearsurface moisture. Lag composites show a building of surface net radiation anomalies throughout the suppressed phase, maximizing at $10-15 \mathrm{~W} \mathrm{~m}^{-2}$ over DWL locations, suggesting that radiative destabilization is most significant over DWLs at the end of the suppressed phase (not shown). 
Daily Anomalous Evolution -14 to 14 days since start of $D$

(a) (E-P)obs-ERA5 MFD

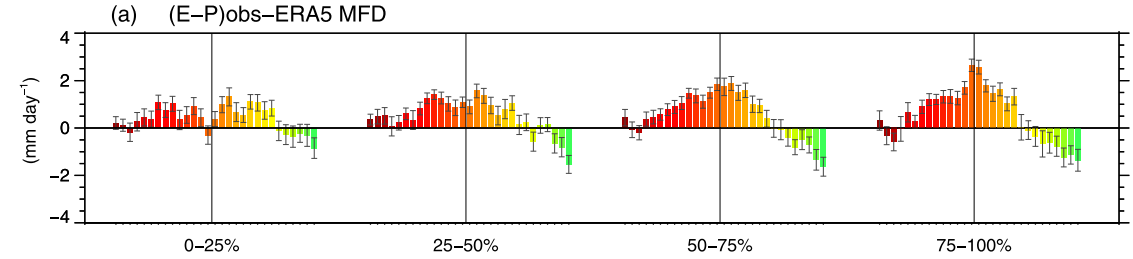

(b) (E-P)obs-MERRA-2 MFD

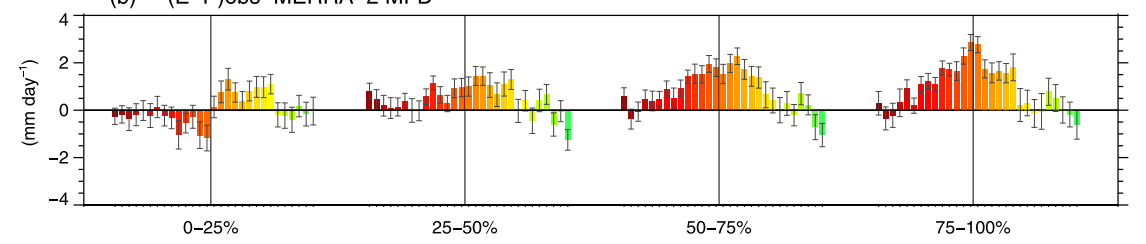

(c) $\operatorname{ERA} 5(\mathrm{dW} / \mathrm{dt})$

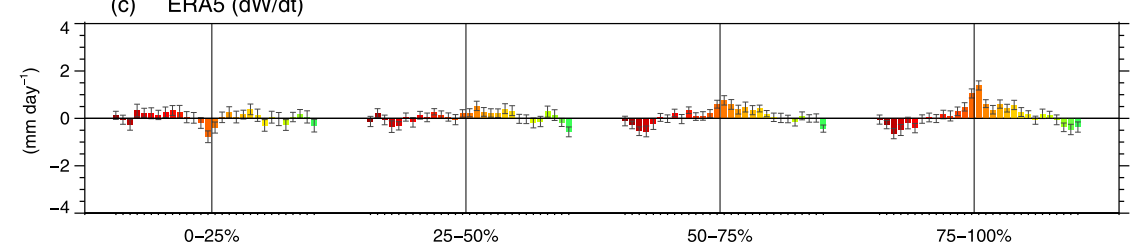

(d) MERRA-2 (dW/dt)

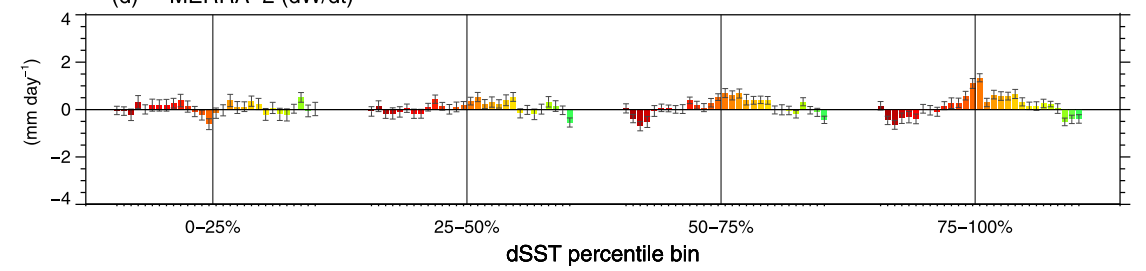

FIG. 10. The anomalous evolution of the variables from Fig. 9 composited by dSST percentile bins (left to right columns) 14 days before and after the start of the transition phase (vertical black line). Colors represent approximate MJO phase color from Fig. 2. Standard errors are displayed as error bars.

\section{Discussion and conclusions}

Our results indicate that prior to MJO initiation local air-sea coupling results in diurnal warm layers (DWLs) that contribute to moistening the column by increasing the relative contribution of local evaporation from air-sea fluxes of heat and moisture within a background of large-scale moisture divergence and significantly reduced precipitation. An associated reduction (increase) in convective inhibition (instability) generated by accumulated warming and moistening along with increased radiative instability provides a late afternoon forcing mechanism for moisture convergence and the daytime development of cumuliform clouds over broad areas of persistent DWLs.

Combining R/V Revelle sounding profiles, surface fluxes, precipitation, and near-surface meteorology with matching parameters from satellite, we find good agreement especially between latent heat flux and near-surface wind speed. The SeaFlux SST agrees closely $(r=0.8)$ with the sea snake SST; however, CERES Ed4A upwelling surface longwave flux fails to capture the $5-15 \mathrm{~W} \mathrm{~m}^{-2}$ diurnal variations observed by the $\mathrm{R} / \mathrm{V}$ radiometer leading to a systematic low bias compared to DYNAMO measurements. The observed CERES clear-sky
OLR better captures the warming of the surface throughout the suppressed phase during DYNAMO MJO-1; however, diurnal variability is small. DWL amplitude maximizes during the suppressed and transition phases of DYNAMO MJO-2 as indicated by both the sea snake and satellite. MJO-2 develops into more frequent and intense convection during the active phase than MJO-1. When aligned with sounding-derived moistening and instability, these strong DWL days are associated with reduced middle-tropospheric humidity and large diurnal amplitude of surface warming, evaporation, instability, and moistening.

Compositing over $44 \mathrm{MJO}$ events and four dSST percentiles defined as separate locations in each suppressed phase, satellite retrievals reveal greater evaporation diurnal amplitude, less surface wind, $\sim 3$-times-reduced precipitation, and a greater daytime increase of low clouds over DWLs. Given that afternoon cumuliform clouds under large-scale subsidence are unlikely to produce precipitation, their detrainment likely acts to moisten the lower to middle troposphere for MJO initiation. The clearer conditions linked with DWLs lead to enhanced longwave cooling compared to the lowest-dSST bin where enhanced upper- and midlevel cloud cover absorbs and reemits 
(a)

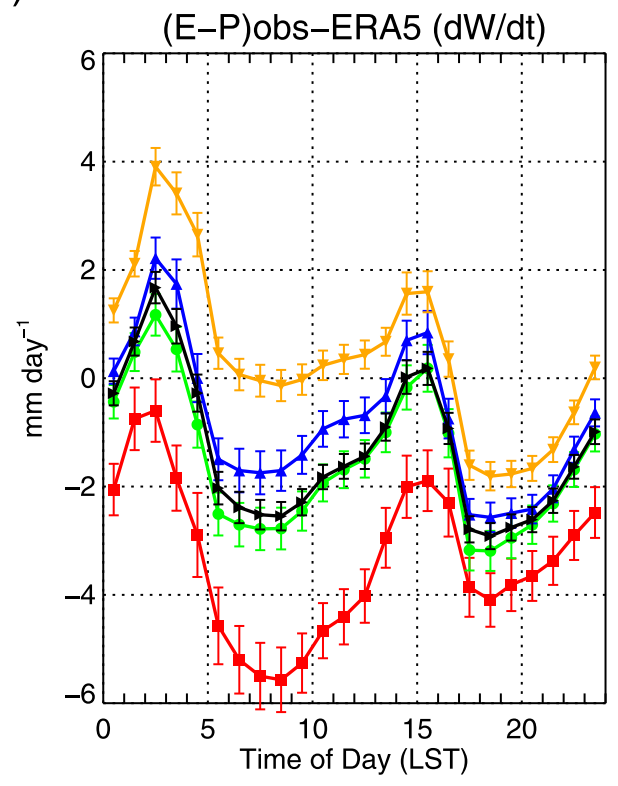

(b)

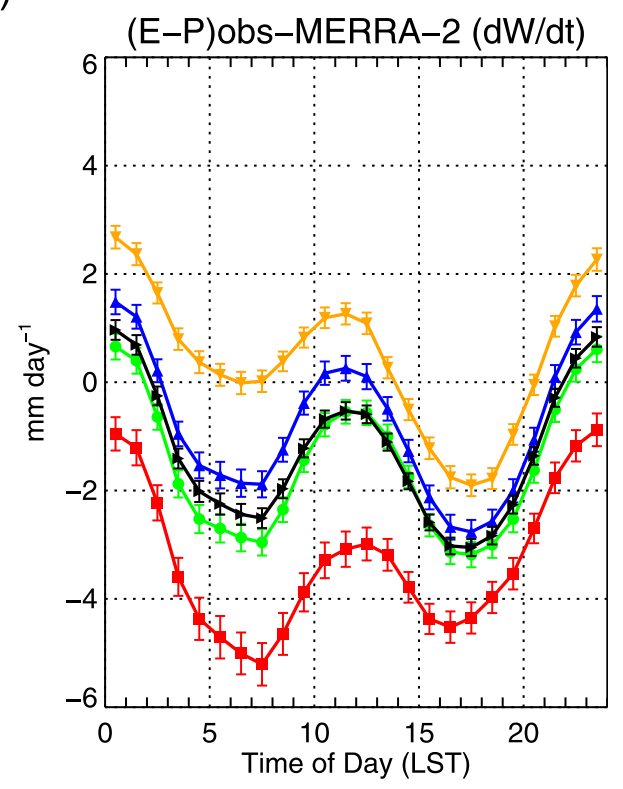

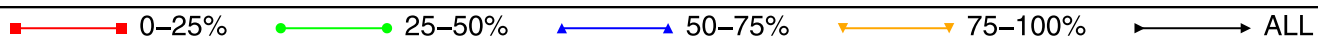

(c)

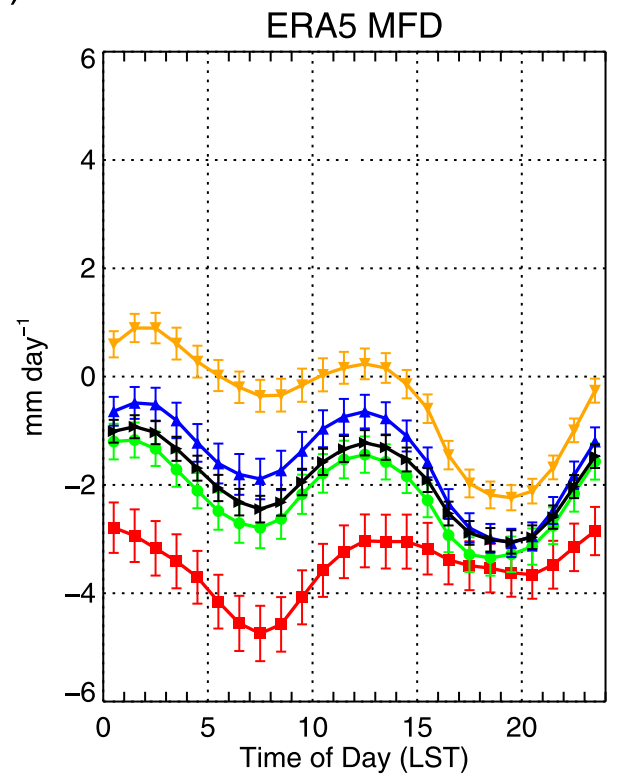

(d)

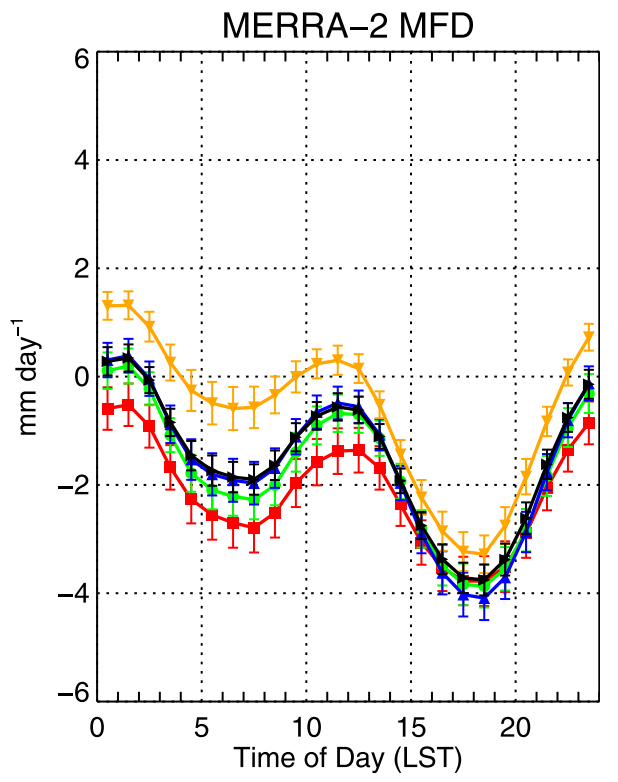

\section{Phase C composites over: [10S - 5N; $50-100 E]$}

FIG. 11. The suppressed phase diurnal cycle composited by dSST percentiles: 0th-25th (red line), 25th-50th (green line), 50th-75th (blue line), 75th-100th (orange line), and 0th-100th (black line) of (a) residual MFD using ERA5 moisture tendency, (b) residual MFD using MERRA-2 moisture tendency, (c) ERA5 MFD, and (d) MERRA-2 MFD. Standard errors are displayed as error bars.

(absorbs and reflects) longwave (shortwave) radiation. Radiative heating acts as a positive (negative) feedback toward generating convective instability over DWLs (nonDWLs) during daytime. As the MJO suppressed phase progresses, conditions become increasingly clear and calm over locations with persistent DWLs, leading to $10-15 \mathrm{~W} \mathrm{~m}^{-2}$ net surface radiative flux anomalies driven by accumulated warming of the ocean surface and boundary layer. 
Daily Anomalous Evolution -14 to 14 days since start of $D$

(a) (E-P)obs-ERA5 (dW/dt)

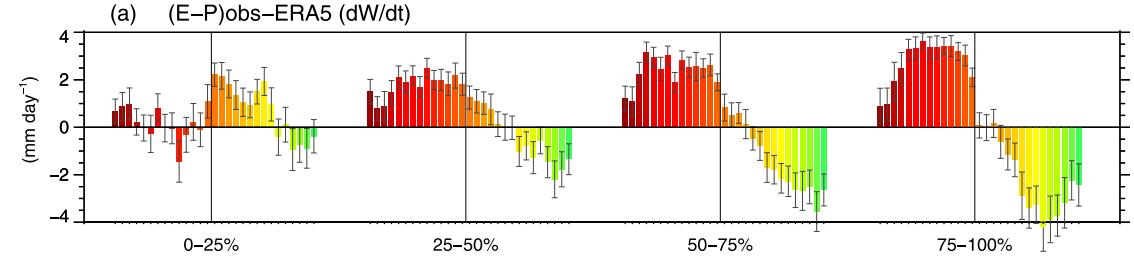

(b) (E-P)obs-MERRA-2 (dW/dt)

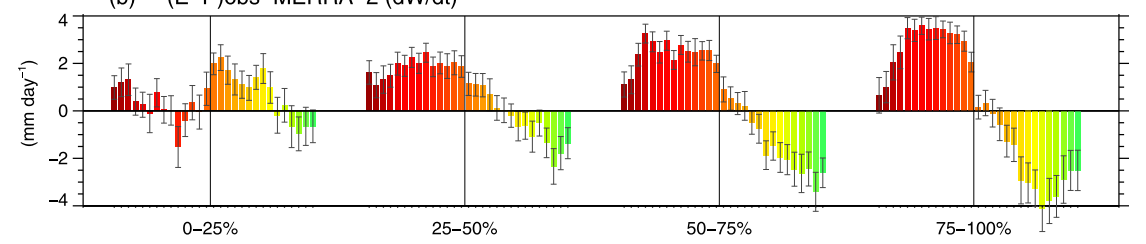

(c) ERA5 MFD

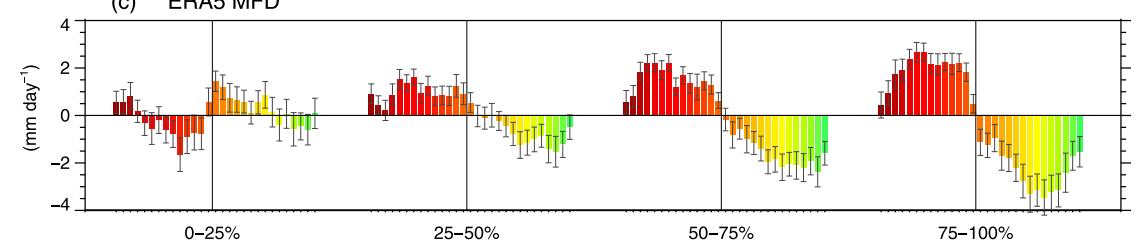

(d) MERRA-2 MFD

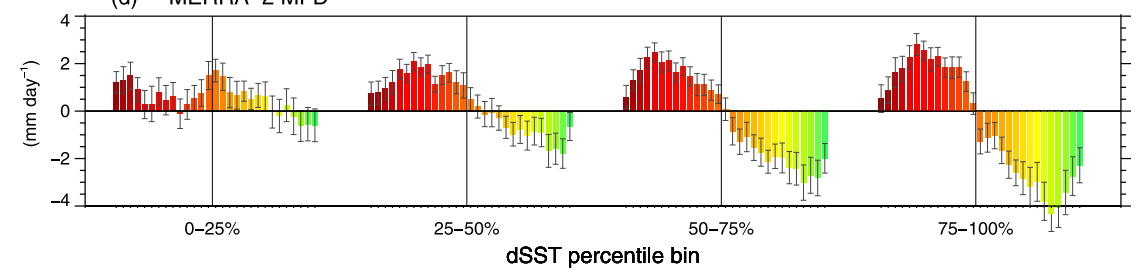

FIG. 12. The anomalous evolution of the variables from Fig. 11 composited by dSST percentile bins (left to right columns) 14 days before and after the start of the transition phase (vertical black line). Colors represent approximate MJO phase color from Fig. 2. Standard errors are displayed as error bars.

DWL locations correspond to significantly greater afternoon moistening rates $\left(\sim 20 \%-50 \%\right.$ or $\sim 1 \mathrm{~mm}$ day $\left.^{-1}\right)$ either when computed as the residual of satellite physics and model dynamics or when compositing assimilated moisture tendencies of MERRA-2 and ERA5. The former approach yields much more significant afternoon moistening over DWLs. Compared to satellite microwave precipitation and evaporation retrievals, ERA5 better captures the observed diurnal sensitivity resulting in greater relative late afternoon moistening over DWL locations. The lower spatial resolution and lack of air-sea coupling parameterizations in MERRA-2 may contribute to its weaker dynamical sensitivity to dSST regime. Convective parameterizations in both reanalyses produce too much precipitation over DWLs at all times of the day, leading to excessive vertical motion and evaporation compared to observations.

When computed as the residual of satellite physics and assimilated moisture tendency, MFD is more sensitive to dSST regime and better represents the contrast between the largescale subsidence over DWLs and rising motion associated with deep convection over weak DWL locations. Both ERA5 and MERRA-2 show rapid 3-4 mm day ${ }^{-1}$ anomalous MFD decreases during the final $48 \mathrm{~h}$ of the suppressed phase that are unmatched by changes in anomalous precipitation. Therefore, large-scale dynamical changes drive much of the moistening of the suppressed MJO environment within the models. However, when computed as a residual, the change in anomalous moisture flux divergence is smaller during the end of the suppressed phase, acting to increase the relative role of local evaporation and smaller-scale dynamical changes on moistening the column.

The control of the columnar water budget shifts from a strong balance between large precipitation and moisture convergence values in the lowest-dSST bin to one where local evaporation contributes a larger relative role for the higherdSST conditions where precipitation and moisture flux convergence are smaller. When composited by lag, the moistening rate increases throughout the course of the suppressed phase for the two highest-dSST bins, maximizing at over $2 \mathrm{~mm} \mathrm{day}^{-1}$ for the highest-dSST bin at the start of the transition phase. The rapid increase in moistening at the end of the suppressed phase appears to be driven primarily by a decrease in anomalous moisture flux divergence that is outpaced by the sharp reduction in precipitation. 
(a)

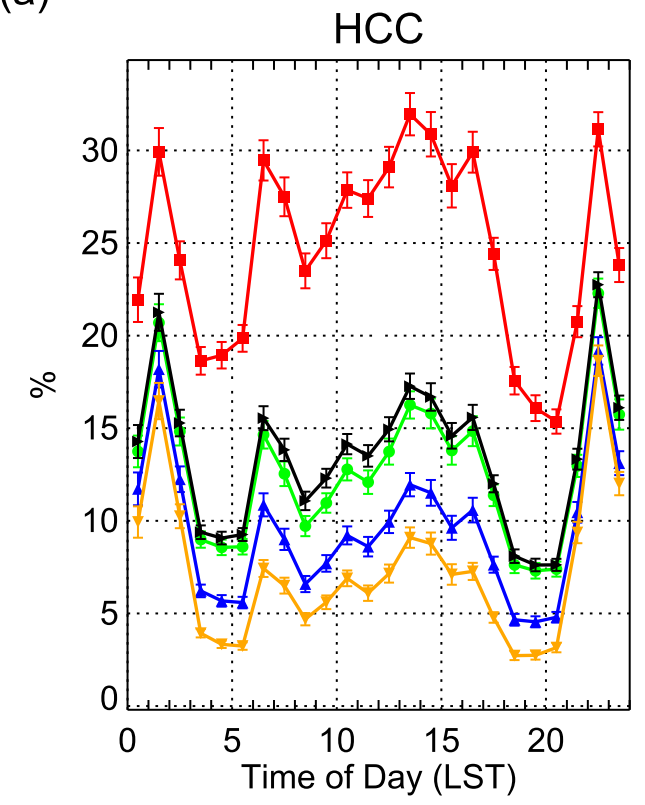

(b)

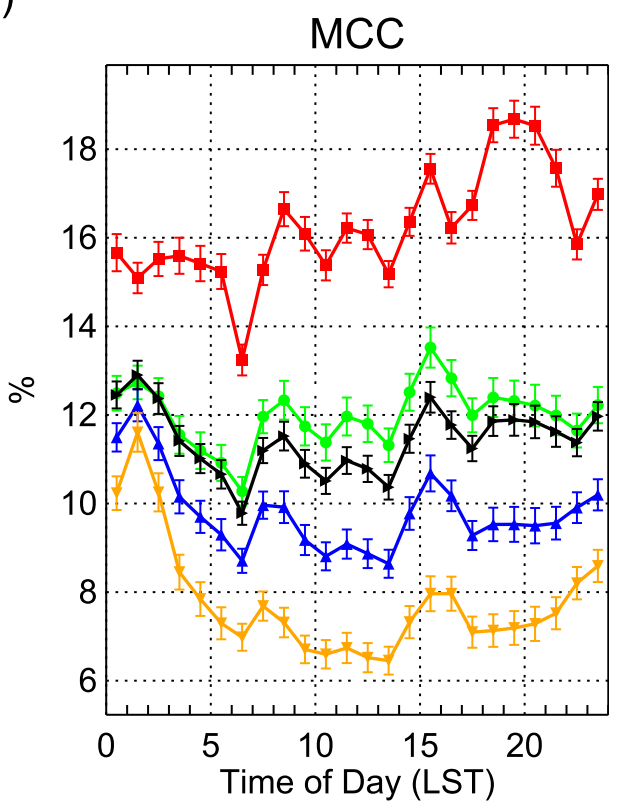

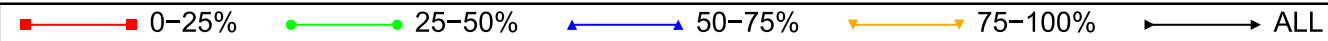

(c)

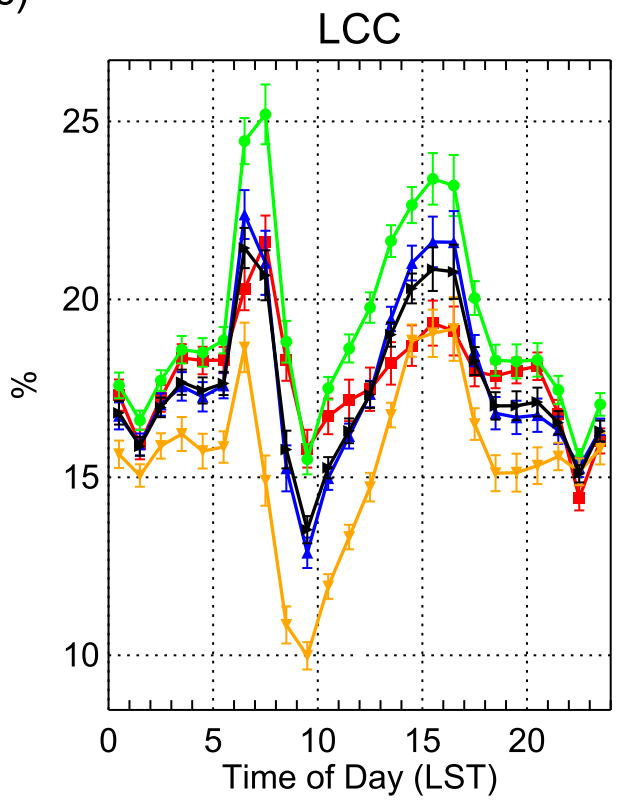

(d)

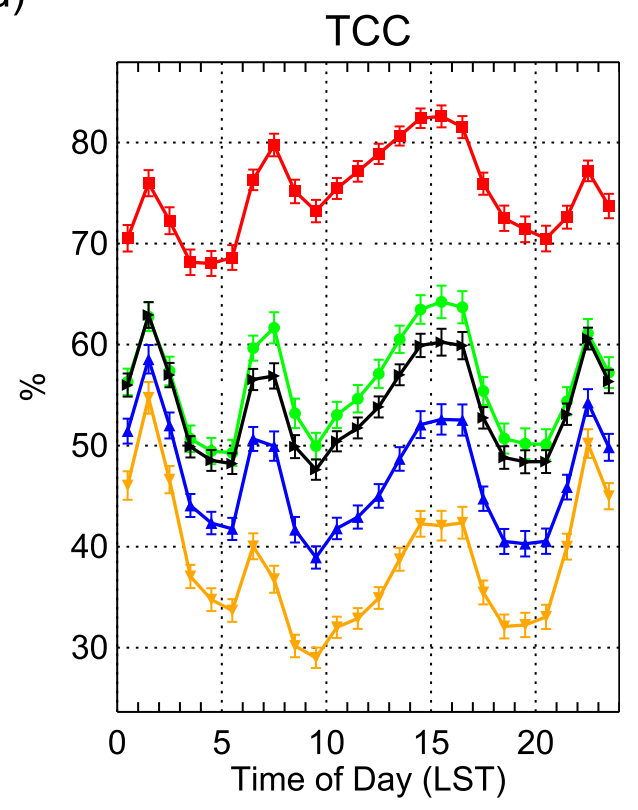

\section{Phase C composites over: [10S - 5N; $50-100 E]$}

FIG. 13. The suppressed phase diurnal cycle composited by dSST percentiles: 0th-25th (red line), 25th-50th (green line), 50th-75th (blue line), 75th-100th (orange line), and 0th-100th (black line) of (a) high cloud cover, (b) middle cloud cover, (c) low cloud cover, and (d) total cloud cover. Standard errors are displayed as error bars.

In summation, the results here indicate the importance of large-scale dynamical forcing together with the potential for local enhancement and rectification of surface diurnal warming toward moistening and destabilization of the pre-MJO onset environment. Larger-scale dynamics are clearly important in driving the upper-atmospheric divergence patterns that drive mid- to upper-level cloud responses and result in areas with preferentially stronger surface warming due to increased 

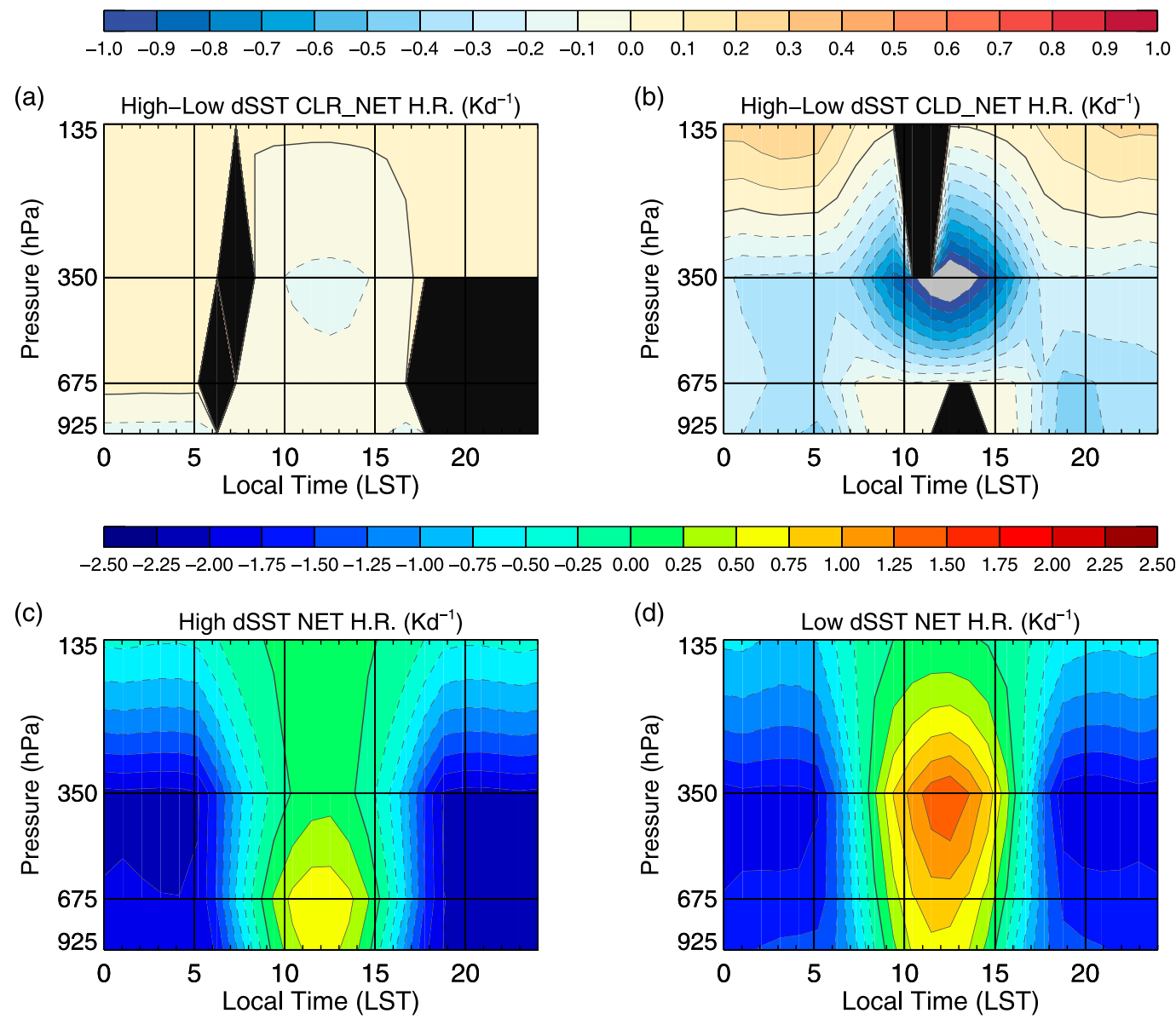

FIG. 14. The suppressed phase composite heating rate diurnal cycle of (a) difference in clear-sky net between the high- and low-dSST bins, (b) difference in cloud net between the high- and low-dSST bins, (c) all-sky net for the high-dSST bin, and (d) all-sky net for the low-dSST bin. Values outside the range are filled gray. Statistically insignificant differences (two-sample $t$ test; $p>0.05$ ) are filled black.

downwelling shortwave radiation and weaker surface winds. However, low cloud cover variability exhibits a remarkably stable bimodality irrespective of the processes controlling the middle and upper troposphere; this likely reflects a stronger connection between the low cloud and diurnal boundary layer variability. Within this latter context, the stronger diurnal surface warming appears to be differentially associated with lower precipitation, weak afternoon moisture convergence, radiative destabilization, and a robust afternoon peak in evaporation. The latter is driven by a direct contribution of increased surface temperatures to the skin sea surface humidity in a drier environment despite the generally weaker winds. As the generally dominant balance between moisture convergence and precipitation weakens, the local evaporation becomes a relatively more important component of the water (and moist static energy) budget. It is beyond the scope of the present paper to determine the source and scale of the dynamical changes; however, future studies could use cloudresolving models to elucidate the impact of diurnal warm layers on the local circulation and moistening in the suppressed MJO environment. As other modeling studies and these observational results indicate, it is important to include the diurnal warming of the sea surface to properly evaluate the role of airsea coupling as part of the MJO evolution.

Acknowledgments. The authors thank three anonymous reviewers for providing comments and criticism that has significantly improved the manuscript. CERES SYN1deg Ed4A data were obtained from the NASA Langley Research Center Atmospheric Science Data Center (https://doi.org/10.5067/ TERRA+AQUA/CERES/SYN1DEG-1HOUR_L3.004A). ERA5 data were downloaded from the Copernicus Climate Change Service using the Climate Data Store API (https:// doi.org/10.24381/cds.adbb2d47). MERRA-2 data were downloaded from the Goddard Earth Sciences Data and Information Services Center (GES DISC) (https://doi.org/10. 5067/Q5GVUVUIVGO7). SeaFlux version 3 data are available from the Global Hydrology Resource Center data archive (https://dx.doi.org/10.5067/SEAFLUX/DATA101). IMERG v06 data were downloaded from GES DISC (https://doi.org/10.5067/ 
(a)

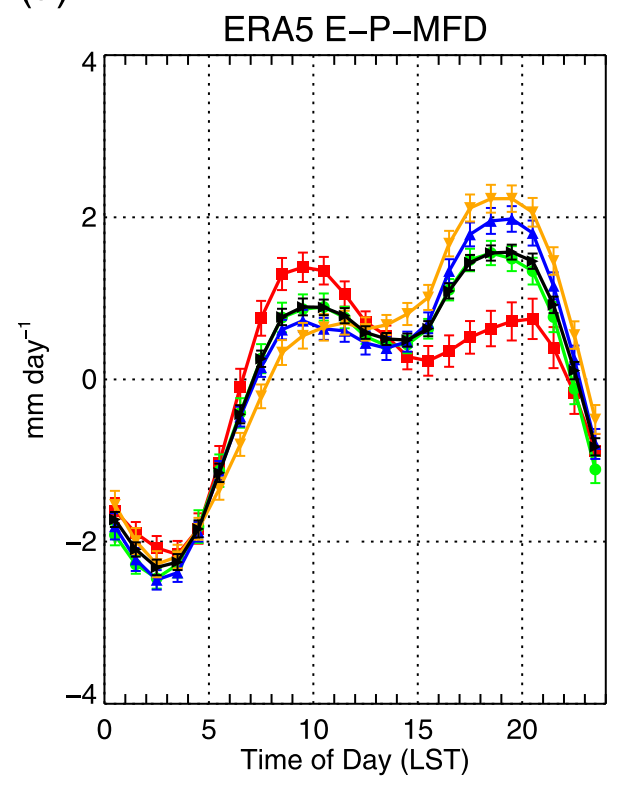

(b)

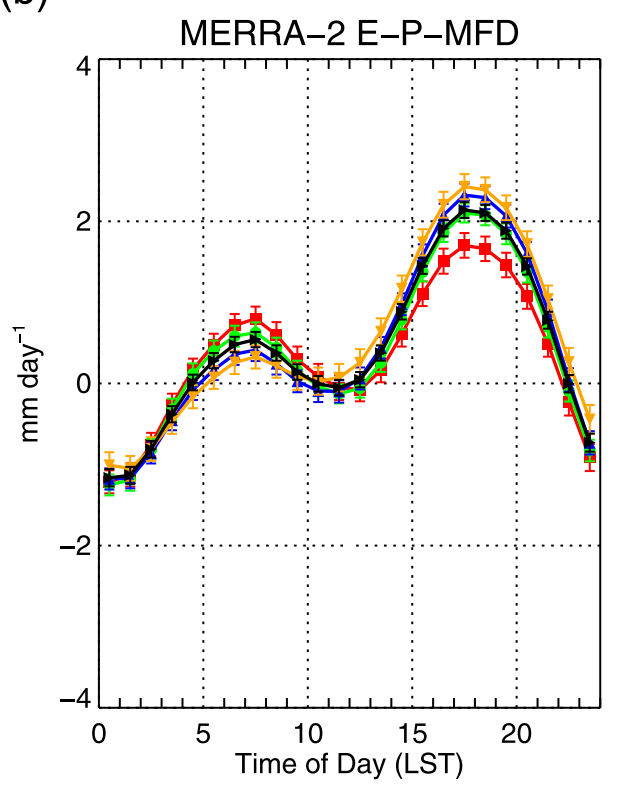

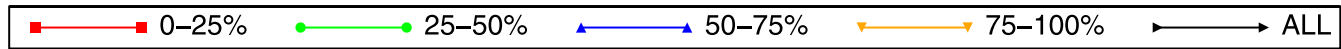

(c)

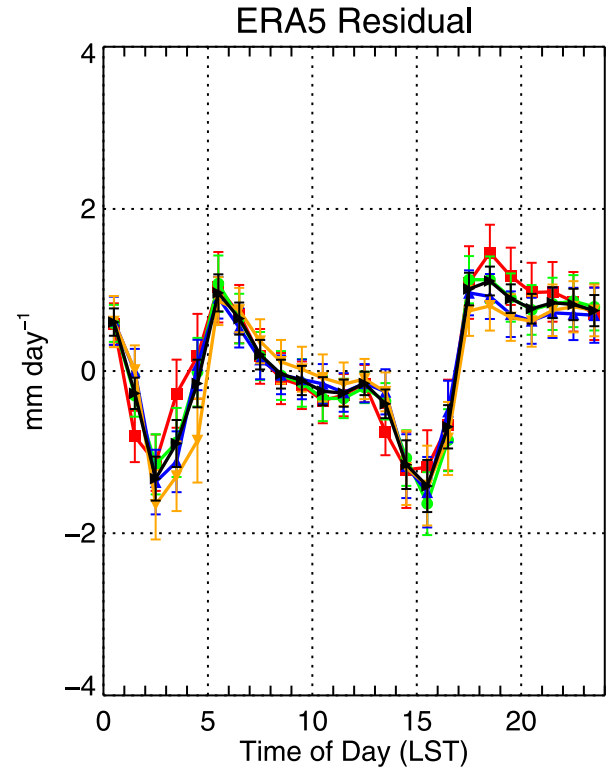

(d)

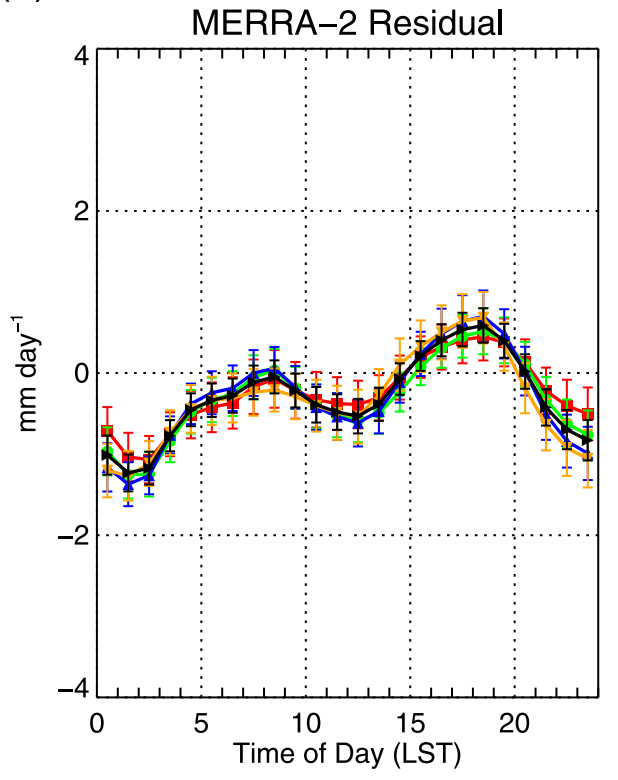

\section{Phase C composites over: [10S - 5N; $50-100 E]$}

FIG. A1. The suppressed phase diurnal cycle composited by dSST percentiles: 0th-25th (red line), 25th-50th (green line), 50th-75th (blue line), 75th-100th (orange line), and 0th-100th (black line) of (a) residual moistening rate using ERA5 physics and dynamics, (b) residual moistening rate using MERRA-2 physics and dynamics, (c) ERA-5 residual model error, and (d) MERRA-2 residual model error. Standard errors are displayed as error bars.

GPM/IMERG/3B-HH/06). The R/V Roger Revelle data were collected as part of DYNAMO, which was sponsored by NSF, NOAA, ONR, DOE, NASA, and JAMSTEC. The involvement of the NSF-sponsored National Center for Atmospheric Research
(NCAR) Earth Observing Laboratory (EOL) is acknowledged. The data are archived at the DYNAMO Data Archive Center maintained by NCAR EOL. This work was funded by Grant NNH13ZDA001N-TERAQ. 
(a) ERA5 E-P-MFD

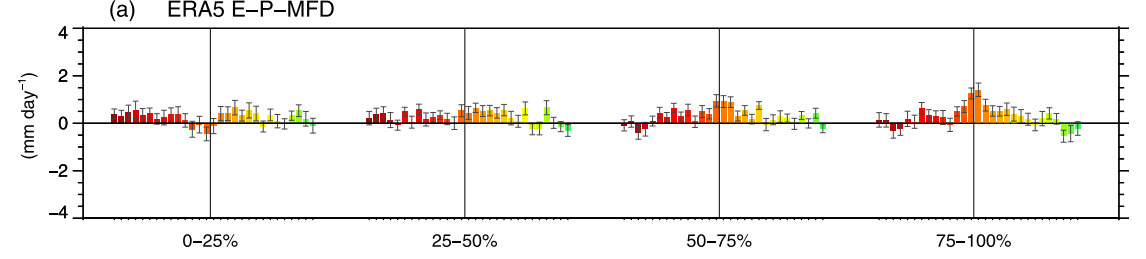

(b) MERRA-2 E-P-MFD

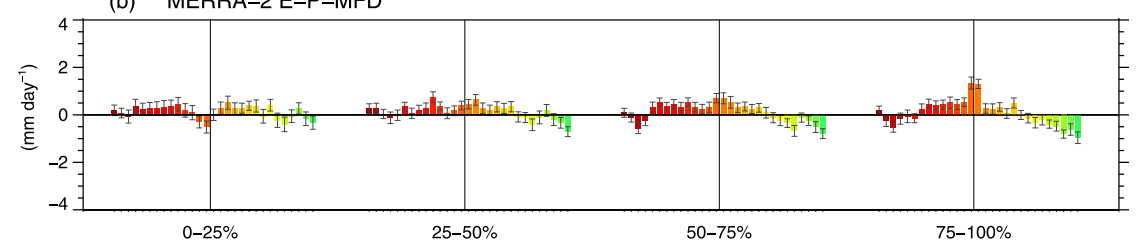

(c) ERA5 Residual

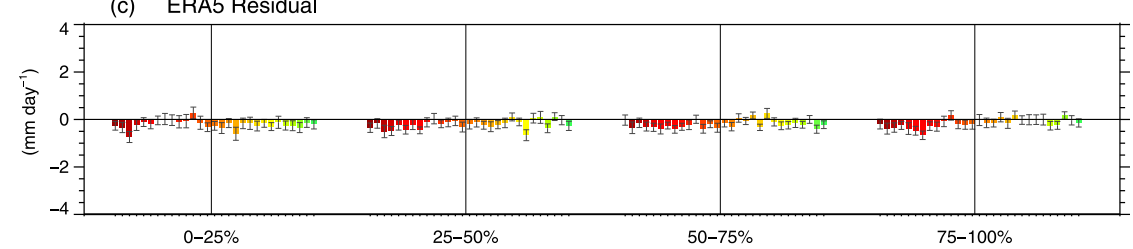

(d) MERRA-2 Residual

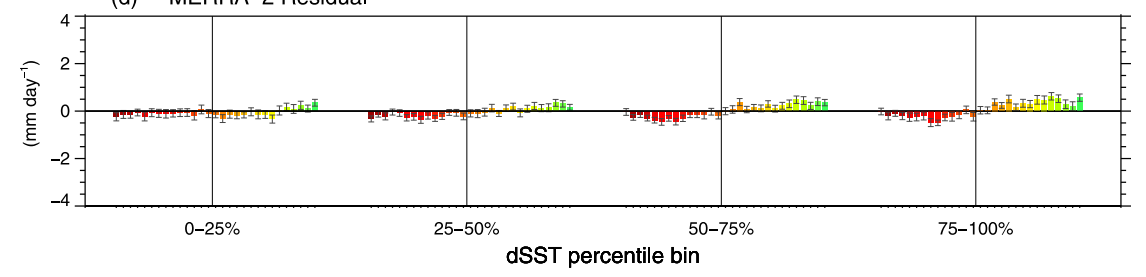

FIG. A2. The anomalous evolution of the variables from Fig. A1 composited by dSST percentile bins (left to right columns) 14 days before and after the start of the transition phase (vertical black line). Colors represent approximate MJO phase color from Fig. 2. Standard errors are displayed as error bars.

Data availability statement. No new data were created during the study.

\section{APPENDIX}

\section{Reanalysis Moisture Budget Sensitivity to dSST}

Figures A1a and A1b show the composite diurnal cycle of ERA5 and MERRA-2 moistening rates by replacing $E, P$, and MFD in Eq. (3) with model values. Despite large differences and errors in the model physics and dynamics, the model residual moistening rate composites are remarkably similar. Agreement in hourly averaged moistening between the model moisture budget and the assimilated moisture tendency (Figs. 9c,d) leads to small $\varepsilon$ (Figs. A1c,d). Persistent ERA5 convective rainfall rates (Fig. $7 b$ ) result in enhanced drying before sunrise (Fig. A1a) compared to MERRA-2 (Fig. A1b). However, this early morning drying is $1-2 \mathrm{~mm}_{\text {day }}{ }^{-1}$ weaker than in Fig. 9c, resulting in larger early morning $\boldsymbol{\varepsilon}$ for ERA5 (Fig. A1c) than MERRA-2 (Fig. A1d). The stronger diurnal sensitivity of $P$ (Figs. 7b,c) and MFD (Figs. 11c,d) to dSST in ERA5 contributes to greater moistening rate differences between low and high-dSST locations, especially during daytime (Figs. A1a,b).

Anomalous moistening varies more strongly over the composite MJO cycle using model physics and dynamics (Figs. A2a,b) compared to assimilated moisture tendency (Figs. 9c,d). Over DWL locations, anomalous moistening persists for over a week before the start of the transition phase (right two columns, Figs. A2a,b). Residual errors in the model physics and dynamics contribute to slight overestimation (underestimation) of suppressed (active) phase anomalous moistening for both models (Figs. A2c,d).

\section{REFERENCES}

Bellenger, H., Y. N. Takayabu, T. Ushiyama, and K. Yoneyama, 2010: Role of diurnal warm layers in the diurnal cycle of convection over the tropical Indian Ocean during MISMO. Mon. Wea. Rev., 138, 2426-2433, https://doi.org/10.1175/ 2010MWR3249.1.

Bernie, D. J., E. Guilyardi, G. Madec, J. M. Slingo, S. J. Woolnough, and J. Cole, 2008: Impact of resolving the diurnal cycle in an ocean-atmosphere GCM. Part II: A diurnally coupled CGCM. Climate Dyn., 31, 909-925, https://doi.org/ 10.1007/s00382-008-0429-z. 
Brown, P. J., and C. D. Kummerow, 2014: An assessment of atmospheric water budget components over tropical oceans. J. Climate, 27, 2054-2071, https://doi.org/10.1175/JCLI-D-1300385.1.

C3S, 2017: ERA5: Fifth generation of ECMWF atmospheric reanalyses of the global climate. Copernicus Climate Change Service Climate Data Store (CDS), accessed 20 November 2019, https://doi.org/10.24381/cds.adbb2d47.

CERES Science Team, 2015: CERES SYN1deg, version edition 4A. Subset: Daily, October 2000-March 2018, NASA Atmospheric Science Data Center, accessed 5 February 2019, https://doi.org/ 10.5067/TERRA + AQUA/CERES/SYN1DEG-1HOUR_ L3.004A.

Chen, S., and Coauthors, 2015: A study of CINDY/DYNAMO MJO suppressed phase. J. Atmos. Sci., 72, 3755-3779, https:// doi.org/10.1175/JAS-D-13-0348.1.

Ciesielski, P. E., and Coauthors, 2014: Quality-controlled upper-air sounding dataset for DYNAMO/CINDY/AMIE: Development and corrections. J. Atmos. Oceanic Technol., 31, 741-764, https:// doi.org/10.1175/JTECH-D-13-00165.1.

—, R. H. Johnson, X. Jiang, Y. Zhang, and S. Xie, 2017: Relationships between radiation, clouds, and convection during DYNAMO. J. Geophys. Res. Atmos., 122, 2529-2548, https://doi.org/10.1002/2016JD025965.

Clayson, C. A., and A. S. Bogdanoff, 2013: The effect of diurnal sea surface temperature warming on climatological air-sea fluxes. J. Climate, 26, 2546-2556, https://doi.org/10.1175/JCLI-D-1200062.1.

DeMott, C. A., N. P. Klingaman, and S. J. Woolnough, 2015: Atmosphere-ocean coupled processes in the Madden-Julian oscillation. Rev. Geophys., 53, 1099-1154, https://doi.org/10.1002/ 2014RG000478.

—, J. J. Benedict, N. P. Klingaman, S. J. Woolnough, and D. A. Randall, 2016: Diagnosing ocean feedbacks to the MJO: SST-modulated surface fluxes and the moist static energy budget. J. Geophys. Res., 121, 8350-8373, https://doi.org/10.1002/2016JD025098.

de Szoeke, S. P., and E. D. Maloney, 2020: Atmospheric mixed layer convergence from observed MJO sea surface temperature anomalies. J. Climate, 33, 547-558, https://doi.org/10. 1175/JCLI-D-19-0351.1.

_ J. B. Edson, J. R. Marion, C. W. Fairall, and L. Bariteau, 2015: The MJO and air-sea interaction in TOGA COARE and DYNAMO. J. Climate, 28, 597-622, https://doi.org/10.1175/ JCLI-D-14-00477.1.

Doelling, D. R., and Coauthors, 2013: Geostationary enhanced temporal interpolation for CERES flux products. J. Atmos. Oceanic Technol., 30, 1072-1090, https://doi.org/10.1175/JTECH-D-1200136.1.

—, C. O. Haney, B. R. Scarino, A. Gopalan, and R. Bhatt, 2015: Improvements to the geostationary visible imager ray-matching calibration algorithm for CERES edition 4. J. Atmos. Oceanic Technol., 33, 2579-2598, https://doi.org/10.1175/JTECH-D-16-0113.1.

- M. Sun, L. T. Nguyen, M. L. Nordeen, C. O. Haney, D. F. Keyes, and P. E. Mlynczak, 2016: Advances in geostationaryderived longwave fluxes for the CERES Synoptic (SYN1deg) product. J. Atmos. Oceanic Technol., 33, 503-521, https:// doi.org/10.1175/JTECH-D-15-0147.1.

ECMWF, 2015: IFS documentation-Cy41r2, Part IV: Physical Processes; operational implementation 8 March 2015, ECMWF, https://www.ecmwf.int/node/16648.

Edson, J. B., and Coauthors, 2013: On the exchange of momentum over the open ocean. J. Phys. Oceanogr., 43, 1589-1610, https://doi.org/10.1175/JPO-D-12-0173.1.
Fu, Q., and K. N. Liou, 1993: Parameterization of the radiative properties of cirrus clouds. J. Atmos. Sci., 50, 20082025, https://doi.org/10.1175/1520-0469(1993)050<2008: POTRPO $>2.0 . \mathrm{CO} ; 2$.

, — - M. C. Cribb, T. P. Charlock, and A. Grossman, 1997: Multiple scattering parameterization in thermal infrared radiative transfer. J. Atmos. Sci., 54, 2799-2812, https://doi.org/ 10.1175/1520-0469(1997)054<2799:MSPITI>2.0.CO;2.

Gelaro, R., and Coauthors, 2017: The Modern-Era Retrospective Analysis for Research and Applications, version 2 (MERRA-2). J. Climate, 30, 5419-5454, https://doi.org/10.1175/JCLI-D16-0758.1.

GMAO, 2015a: MERRA-2 tavg1_2d_flx_Nx: 2d, 1-Hourly, TimeAveraged, Single-Level, Assimilation, Surface Flux Diagnostics V5.12.4, Goddard Earth Sciences Data and Information Services Center (GES DISC), accessed 15 August 2020, https://doi.org/10.5067/7MCPBJ41Y0K6.

_- 2015b: MERRA-2 tavg1_2d_int_Nx: 2d,1-Hourly, TimeAveraged, Single-Level, Assimilation, Vertically Integrated Diagnostics V5.12.4, GES DISC, accessed 15 August 2020, https://doi.org/10.5067/Q5GVUVUIVGO7.

2015c: MERRA-2 tavg1_2d_slv_Nx: 2d,1-Hourly, TimeAveraged, Single-Level, Assimilation, Single-Level Diagnostics V5.12.4, GES DISC, accessed 15 August 2020, https://doi.org/ 10.5067/VJAFPLI1CSIV.

Huffman, G. J., and Coauthors, 2007: The TRMM Multisatellite Precipitation Analysis (TMPA): Quasi-global, multiyear, combinedsensor precipitation estimates at fine scales. J. Hydrometeor., 8, 38-55, https://doi.org/10.1175/JHM560.1.

_ E. F. Stocker, D. T. Bolvin, E. J. Nelkin, and J. Tan, 2019a: GPM IMERG Final Precipitation L3 half hourly $0.1^{\circ} \times 0.1^{\circ}$ V06, Goddard Earth Sciences Data and Information Services Center (GES DISC), accessed 2 December 2019, https:// doi.org/10.5067/GPM/IMERG/3B-HH/06.

— (GPM) Integrated Multi-Satellite Retrievals for GPM (IMERG). NASA/GSFC Algorithm Theoretical Basis Doc., version 06, 38 pp. Joyce, R. J., and P. Xie, 2011: Kalman filter-based CMORPH. J. Hydrometeor., 12, 1547-1563, https://doi.org/10.1175/JHMD-11-022.1.

Kato, S., T. P. Ackerman, J. H. Mather, and E. E. Clothiaux, 1999: The k-distribution method and correlated-k approximation for a shortwave radiative transfer model. J. Quant. Spectrosc. Radiat. Transfer, 62, 109-121, https://doi.org/10.1016/S00224073(98)00075-2.

- F. G. Rose, and T. P. Charlock, 2005: Computation of domain averaged irradiance using satellite derived cloud properties. J. Atmos. Oceanic Technol., 22, 146-164, https://doi.org/ 10.1175/JTECH-1694.1.

_, and Coauthors, 2019: Radiative heating rates computed with clouds derived from satellite-based passive and active sensors and their effects on generation of available potential energy. J. Geophys. Res. Atmos., 124, 1720-1740, https://doi.org/ 10.1029/2018JD028878.

Kerns, B. W., and S. S. Chen, 2016: Large-scale precipitation tracking and the MJO over the Maritime Continent and IndoPacific warm pool. J. Geophys. Res. Atmos., 121, 8755-8776, https://doi.org/10.1002/2015JD024661.

Kiladis, G. N., J. Dias, K. H. Straub, M. C. Wheeler, S. N. Tulich, K. Kikuchi, K. M. Weickmann, and M. J. Ventrice, 2014: A comparison of OLR and circulation-based indices for tracking the MJO. Mon. Wea. Rev., 142, 1697-1715, https://doi.org/ 10.1175/MWR-D-13-00301.1. 
Kim, D., J.-S. Kug, and A. H. Sobel, 2014: Propagating versus nonpropagating Madden-Julian oscillation events. J. Climate, 27, 111-125, https://doi.org/10.1175/JCLI-D-13-00084.1.

Klingaman, N. P., and S. J. Woolnough, 2014: The role of air-sea coupling in the simulation of the Madden-Julian oscillation in the Hadley Centre model. Quart. J. Roy. Meteor. Soc., 140, 2272-2286, https://doi.org/10.1002/qj.2295.

Kratz, D. P., and F. G. Rose, 1999: Accounting for molecular absorption within the spectral range of the CERES window channel. J. Quant. Spectrosc. Radiat. Transfer, 61, 83-95, https://doi.org/10.1016/S0022-4073(97)00203-3.

Madden, R. A., and P. R. Julian, 1971: Detection of a 40-50-day oscillation in the zonal wind in the tropical Pacific. J. Atmos. Sci., 28, 702-708, https://doi.org/10.1175/15200469(1971)028<0702:DOADOI >2.0.CO;2.

Matthews, A. J., 2008: Primary and successive events in the Madden-Julian Oscillation. Quart. J. Roy. Meteor. Soc., 134, 439-453, https://doi.org/10.1002/qj.224.

Minnis, P., and Coauthors, 2011: CERES Edition-2 cloud property retrievals using TRMM VIRS and Terra and Aqua MODIS data-Part I: Algorithms. IEEE Trans. Geosci. Remote Sens., 49, 4374-4400, https://doi.org/10.1109/ TGRS.2011.2144601.

Molod, A., L. Takacs, M. Suarez, and J. Bacmeister, 2015: Development of the GEOS-5 atmospheric general circulation model: Evolution from MERRA to MERRA2. Geosci. Model Dev., 8, 1339-1356, https://doi.org/10.5194/gmd-8-1339-2015.

Reynolds, R. W., N. A. Rayner, T. M. Smith, D. C. Stokes, and W. Wang, 2002: An improved in situ and satellite SST analysis for climate. J. Climate, 15, 1609-1625, https://doi.org/10.1175/ 1520-0442(2002)015<1609:AIISAS > 2.0.CO;2.

—, T. M. Smith, C. Liu, D. B. Chelton, K. S. Casey, and M. G. Schlax, 2007: Daily high-resolution-blended analyses for sea surface temperature. J. Climate, 20, 5473-5496, https:// doi.org/10.1175/2007JCLI1824.1.

Roberts, J. B., C. A. Clayson, F. R. Robertson, and D. Jackson, 2010: Predicting near-surface characteristics from Special Sensor Microwave/Imager using neural networks with a firstguess approach. J. Geophys. Res., 115, D19113, https://doi.org/ 10.1029/2009JD013099.

,-- , and — 2019: Improving near-surface retrievals of surface humidity over the global open oceans from passive microwave observations. Earth Space Sci., 6, 1220-1233, https://doi.org/10.1029/2018EA000436.

$\longrightarrow,-$, and 2020: SeaFlux v3: An updated climate data record of ocean turbulent fluxes. Global Hydrology Resource Center Data Archive, accessed 25 February 2020, https:// doi.org/10.5067/SEAFLUX/DATA101.

Rose, F., T. Charlock, Q. Fu, S. Kato, D. Rutan, and Z. Jin, 2005: CERES proto-edition 3 radiative transfer: Model tests and radiative closure over surface validation sites. 12th Conf. on Atmospheric Radiation, Madison, WI, Amer. Meteor. Soc., P2.4, https://ams.confex.com/ams/Madison2006/techprogram/ paper_112358.htm.

Ruppert, J. H., Jr., 2016: Diurnal timescale feedbacks in the tropical cumulus regime. J. Adv. Model. Earth Syst., 8, 1483-1500, https://doi.org/10.1002/2016MS000713.

— , and R. H. Johnson, 2015: Diurnally modulated cumulus moistening in the preonset stage of the Madden-Julian oscil- lation during DYNAMO. J. Atmos. Sci., 72, 1622-1647, https:// doi.org/10.1175/JAS-D-14-0218.1.

— , and D. Klocke, 2019: The two diurnal modes of tropical upward motion. Geophys. Res. Lett., 46, 2911-2921, https:// doi.org/10.1029/2018GL081806.

Sakaeda, N., G. Kiladis, and J. Dias, 2017: The diurnal cycle of tropical cloudiness and rainfall associated with the MaddenJulian oscillation. J. Climate, 30, 3999-4020, https://doi.org/ 10.1175/JCLI-D-16-0788.1.

— S. W. Powell, J. Dias, and G. N. Kiladis, 2018: The diurnal variability of precipitating cloud populations during DYNAMO. J. Atmos. Sci., 75, 1307-1326, https://doi.org/10.1175/JAS-D-170312.1.

Straub, K. H., 2013: MJO initiation in the real-time multivariate MJO index. J. Climate, 26, 1130-1151, https://doi.org/10.1175/ JCLI-D-12-00074.1.

Taylor, P. C., 2012: Tropical outgoing longwave radiation and longwave cloud forcing diurnal cycles from CERES. J. Atmos. Sci., 69, 3652-3669, https://doi.org/10.1175/JAS-D-12-088.1.

- 2014: Variability of monthly diurnal cycle composites of TOA radiative fluxes in the tropics. J. Atmos. Sci., 71, 754-766, https://doi.org/10.1175/JAS-D-13-0112.1.

Thompson, E. J., J. N. Moum, C. W. Fairall, and S. A. Rutledge, 2019: Wind limits on rain layers and diurnal warm layers. J. Geophys. Res. Oceans, 124, 897-924, https://doi.org/10.1029/ 2018JC014130.

Waite, M. L., and B. Khouider, 2010: The deepening of tropical convection by congestus preconditioning. J. Atmos. Sci., 67, 2601-2615, https://doi.org/10.1175/2010JAS3357.1.

Webster, P. J., C. A. Clayson, and J. A. Curry, 1996: Clouds, radiation, and the diurnal cycle of sea surface temperature in the tropical western Pacific. J. Climate, 9, 1712-1730, https://doi.org/ 10.1175/1520-0442(1996)009<1712:CRATDC >2.0.CO;2.

Wheeler, M. C., and H. H. Hendon, 2004: An all-season real-time multivariate MJO index: Development of an index for monitoring and prediction. Mon. Wea. Rev., 132, 1917-1932, https://doi.org/ 10.1175/1520-0493(2004)132<1917:AARMMI>2.0.CO;2.

Wielicki, B. A., B. R. Barkstrom, E. F. Harrison, R. B. Lee, G. L. Smith, and J. E. Cooper, 1996: Clouds and the Earth's Radiant Energy System (CERES): An Earth observing system experiment. Bull. Amer. Meteor. Soc., 77, 853-868, https://doi.org/ 10.1175/1520-0477(1996)077<0853:CATERE >2.0.CO;2.

Woolnough, S. J., F. Vitart, and M. A. Balmaseda, 2007: The role of the ocean in the Madden-Julian oscillation: Implications for MJO prediction. Quart. J. Roy. Meteor. Soc., 133, 117-128, https://doi.org/10.1002/qj.4.

Young, D. F., P. Minnis, D. R. Doelling, G. G. Gibson, and T. Wong, 1998: Temporal interpolation methods for the Clouds and the Earth's Radiant Energy System (CERES) experiment. J. Appl. Meteor., 37, 572-590, https://doi.org/ 10.1175/1520-0450(1998)037<0572:TIMFTC $>2.0 . C O ; 2$.

Zhao, C.-B., T. Li, and T. Zhou, 2013: Precursor signals and processes associated with MJO initiation over the tropical Indian Ocean. J. Climate, 26, 291-307, https://doi.org/10.1175/JCLID-12-00113.1.

Zhao, N., and T. Nasuno, 2020: How does the air-sea coupling frequency affect convection during the MJO passage? J. Adv. Model. Earth Syst., 12, e2020MS002058, https:// doi.org/10.1029/2020MS002058. 